\title{
Artificial Selection and Domestication: Modern Lessons from Darwin's Enduring Analogy
}

\author{
T. Ryan Gregory
}

Published online: 14 January 2009

(C) Springer Science + Business Media, LLC 2009

\begin{abstract}
It is clear from his published works that Charles Darwin considered domestication to be very useful in exploring and explaining mechanisms of evolutionary change. Not only did domestication occupy the introductory chapter of On the Origin of Species, but he revisited the topic in a two-volume treatise less than a decade later. In addition to drawing much of his information about heredity from studies of domesticated animals and plants, Darwin saw important parallels between the process of artificial selection by humans and natural selection by the environment. There was resistance to this analogy even among Darwin's contemporary supporters when it was proposed, and there also has been disagreement among historians and philosophers regarding the role that the analogy with artificial selection actually played in the discovery of natural selection. Regardless of these issues, the analogy between artificial and natural selection remains important in both research and education in evolution. In particular, the present article reviews ten lessons about evolution that can be drawn from the modern understanding of domestication and artificial selection. In the process, a basic overview is provided of current approaches and knowledge in this rapidly advancing field.
\end{abstract}

Keywords Adaptation - Artificial selection - Crops . Domestication $\cdot$ Evolution $\cdot$ Natural selection

\footnotetext{
T. R. Gregory $(\bowtie)$

Department of Integrative Biology, University of Guelph, Guelph, Ontario N1G 2W1, Canada

e-mail: rgregory@uoguelph.ca
}

\begin{abstract}
Slow though the process of selection may be, if feeble man can do much by his powers of artificial selection, I can see no limit to the amount of change, to the beauty and infinite complexity of the coadaptations between all organic beings, one with another and with their physical conditions of life, which may be effected in the long course of time by nature's power of selection.
\end{abstract}

(Charles Darwin 1859, p.109)

\section{Introduction: Darwin and Domestication}

There is little doubt that Darwin considered the process by which animals and plants are domesticated (artificial selection) as a useful analogy for the mechanism by which adaptive evolution occurs in the wild (natural selection). Referring to the challenge of accounting for the remarkable correspondence between the features of organisms and their environments, Darwin (1859. p. 4) wrote,

At the commencement of my observations it seemed to me probable that a careful study of domesticated animals and of cultivated plants would offer the best chance of making out this obscure problem. Nor have I been disappointed; in this and in all other perplexing cases I have invariably found that our knowledge, imperfect though it be, of variation under domestication, afforded the best and safest clue. I may venture to express my conviction of the high value of such studies, although they have been very commonly neglected by naturalists.

The early notebooks in which he worked out his theory of natural selection are laced with references to domestication (see Evans 1984). In 1839, only months after first developing his theory, Darwin prepared and distributed to experts a pamphlet entitled Questions about the breeding of 
animals in an effort to gain more insight into the workings of heredity (see Vorzimmer 1969a). Domestication was the first topic discussed in his "sketch" of 1842 and his "essay" of 1844, an arrangement that persisted in On the Origin of Species by Means of Natural Selection in 1859. Of course, the Origin was considered by Darwin to be only an "abstract" of a much larger work that he intended to complete later-yet the only topic that ultimately received full treatment was domestication, in a two-volume treatise entitled The Variation of Animals and Plants Under Domestication published in 1868.

As will be seen, Darwin's analogy between artificial and natural selection has been the subject of controversy in terms of both its scientific and historical significance. However, as this article aims to make clear, the analogy remains very useful by providing both a model for contemporary research and a means of illustrating and clarifying key points about adaptive evolution.

\section{Darwin's Three Kinds of Selection}

In The Variation of Animals and Plants Under Domestication, Darwin (1868) considered two types of artificial selection in addition to natural selection ${ }^{1}$ : methodical selection and unconscious selection. As he explained (Darwin 1868, p. 153),

Methodical selection is that which guides a man who systematically endeavours to modify a breed according to some predetermined standard. Unconscious selection is that which follows from men naturally preserving the most valued and destroying the less valued individuals, without any thought of altering the breed.

Darwin's three types of selection-methodical, unconscious, and natural - are united by a fundamental mechanistic similarity, namely that they involve a non-random difference in reproductive success among individuals on the basis of heritable traits. What differs among these processes is simply the reason why some individuals will reproduce while others become genetic dead ends. For obvious reasons, the form of artificial selection that Darwin dubbed methodical selection has also been called "deliberate" or "conscious" or "intentional" selection (e.g., Harlan et al 1973; Heiser 1988; Zohary 2004; Emshwiller 2006). It is sometimes argued that the current use of this concept differs from that initially proposed by Darwin (see Heiser 1988; Zohary 2004), but fundamentally this involves a process

\footnotetext{
${ }^{1}$ In 1871, Darwin introduced the mechanism of sexual selection, which is selection based strictly on reproduction, including competition for mates and mate choice. It generally can be considered a special case of natural selection.
}

whereby humans actively choose individuals from among an available sample in order to preserve, and ultimately enhance, traits of interest. Unconscious selection, by contrast, is a much more passive form of artificial selection and may involve no specific intent whatsoever. Humans still determine which individuals will contribute most to the next generation, but in this case they may do so without the knowledge that this can have a long-term effect. Natural selection resides at the far end of this continuum, whereby the reproductive success of individuals is not determined by selective breeding or cultivation ${ }^{2}$.

\section{The Uses and Usefulness of Darwin's Analogy}

According to Evans (1984), "Darwin's recognition of the power of selection in changing organisms was almost entirely due to what he learned of plant and animal breeding." Certainly, Darwin himself wished to convey that his discovery of natural selection grew from his studies of artificial selection. He indicated in his private autobiography that his recognition of artificial selection as the key process in domestication primed him to conceive of natural selection when he read the essay by Malthus on human populations (Darwin 1958; written in 1876 and first published in 1887). A similar sequence of events was presented by Darwin in letters written to friends before the publication of the Origin $^{3}$. Nonetheless, citing additional evidence such as Darwin's notebooks and his use of other published works, historians and philosophers have continued to debate both the role that artificial selection played (or did not play) in Darwin's development and justification of the concept of natural

\footnotetext{
${ }^{2}$ Humans may nevertheless be responsible for creating the conditions in which natural selection operates. For example, treatment with antibiotics instigates a process of natural selection among bacteria in which mutants that happen to be resistant survive and reproduce more than individuals lacking resistance. Humans may also impose selection in the form of selective predation, for example by capturing large fish and releasing small ones - that is, imposing natural selection for smaller size at maturity (e.g., Jørgensen et al. 2007). See Palumbi (2001a, b) for a discussion of the significant impact humans have by instigating natural selection in other species.

${ }^{3}$ For example, he wrote to Asa Gray on July 20th, 1857, that "all my notion about how species change are derived from long-continued study of the works of (\& converse with) agriculturists \& horticulturists; \& I believe I see my way pretty clearly on the means used by nature to change her species \& adapt them to the wondrous \& exquisitely beautiful contingencies to which every living being is exposed." Later, after receiving Alfred Russel Wallace's sketch outlining his independent discovery of natural selection, Darwin wrote in a letter to Charles Lyell dated June 25th, 1858 that he and Wallace "differ only, that I was led to my views from what artificial selection has done for domestic animals". On April 6th, 1859, he responded to a query from Wallace, "You are right, that I came to the conclusion that selection was the principle of change from the study of domesticated productions; and then reading Malthus I saw at once how to apply this principle."
} 
selection and the nature of the analogy that he intended to draw between artificial and natural selection (e.g., Vorzimmer 1969b; Herbert 1971; Ruse 1973, 1975; Schweber 1977; Kohn 1980; Cornell 1984; Evans 1984; Rheinberger and McLaughlin 1984; Waters 1986; Bartley 1992; Richards 1997; Sterrett 2002; Gildenhuys 2004).

Whether or not Darwin discovered natural selection via the route of artificial selection, he made heavy use of it in arguing for the historical reality of common descent and the efficacy of natural selection. It should be no surprise, then, that the analogy became a target for critics of Darwin's theory following the publication of the Origin (Hull 1973; Evans 1984). More interestingly and as several authors have noted (e.g., Evans 1984; Rheinberger and McLaughlin 1984; Richards 1997; Ross-Ibarra et al. 2007), it was not only Darwin's opponents but also some of his most ardent supporters who questioned the validity of comparing artificial selection with processes occurring in the wild. The example cited most often is that of Alfred Russel Wallace, whose independent discovery of natural selection prompted Darwin to publish the Origin. In his paper presented jointly with Darwin's to the Linnean Society of London in 1858, Wallace went so far as to argue,

We see, then, that no inferences as to varieties in a state of nature can be deduced from the observation of those occurring among domestic animals. The two are so much opposed to each other in every circumstance of their existence, that what applies to the one is almost sure not to apply to the other. Domestic animals are abnormal, irregular, artificial; they are subject to varieties which never occur and never can occur in a state of nature; their very existence depends altogether on human care; so far are many of them removed from that just proportion of faculties, that true balance of organization, by means of which alone an animal left to its own resources can preserve its existence and continue its race.

It bears noting, however, that Wallace's position on this matter appears to have softened over the ensuing decades. In his book Darwinism, published several years after Darwin's death, Wallace (1889, p. vi) indicated his continued preference for data drawn from natural species when he noted that "it has always been considered a weakness in Darwin's work that he based his theory, primarily, on the evidence of variation in domesticated animals and cultivated plants". Yet, he also dedicated a chapter to the topic of domestication, making it clear that he had come to consider the topic a useful one in explaining the operation and importance of selection in nature. His primary focus in this case was on the extensive variation observed among individual plants and animals under domestication, which paralleled that witnessed in nature.
He further noted, in the introduction to the following chapter on natural selection (p. 102-103),

we have seen how similar variations, occurring in cultivated plants and domestic animals, are capable of being perpetuated and accumulated by artificial selection, till they have resulted in all the wonderful varieties of our fruits, flowers, and vegetables, our domestic animals and household pets, many of which differ from each other far more in external characters, habits, and instincts than do species in a state of nature. We have now to inquire whether there is any analogous process in nature, by which wild animals and plants can be permanently modified and new races or new species produced.

Regardless of how the debate surrounding Darwin's use of it is ultimately settled, and despite significant early criticism of its validity, it is evident that the analogy between artificial selection and natural selection continues to be considered useful among modern biologists. In fact, recent discoveries in a range of disciplines from archeology to molecular biology have made Darwin's analogy more relevant than ever. Indeed, the evolution of plants and animals in response to artificial selection is increasingly seen as a very productive model for studying general questions about adaptive evolution (e.g., Gepts 2004; Ross-Ibarra et al. 2007). Artificial selection also remains a useful tool for illustrating key principles in evolutionary biology, especially since most people are familiar with many of the species that have been domesticated and with the general concept of selective breeding.

In this regard, Darwin's use of the analogy in discovering natural selection or his intent in invoking it becomes of secondary importance to the role that the analogy can play in modern evolutionary research and education. Thus, one may still ask, as Darwin did: What is known about artificial selection and domestication, and what can be learned from this about evolution in nature?

In order to highlight the enduring utility of Darwin's emphasis on artificial selection, the remainder of the article presents ten lessons that can be learned from a study of artificial selection and illustrates them with examples drawn from recent studies of well-known species.

\section{Lesson 1: Selection Can Result in Profound Changes}

Though they have since been the focus of much research and are recognized as a classic case of evolution in action (Grant and Grant 2008), Darwin's finches of the Galapagos Islands are not mentioned specifically in the Origin. By contrast, Darwin dedicated several pages to a discussion of domesticated pigeons in the Origin in 1859 and expanded this to a treatment spanning two entire chapters in Variation in 1868. In Darwin's day, pigeon breeding was a common 
Fig. 1 Drawings of four of the six pigeon breeds presented by Darwin (1868), as drawn by Luke Wells. a English pouter, b short-faced English tumbler, c English carrier, d English fantail. As extraordinary as the differences among them appear in these drawings, Darwin (1868) noted that "the characters of the six breeds which have been figured are not in the least exaggerated." Darwin himself became an active breeder of pigeons and attempted not only to demonstrate that all of the fancy breeds produced by artificial selection descended from a single wild species (the rock pigeon, Columba livia) but to reconstruct their historical relationships (Fig. 4)
A
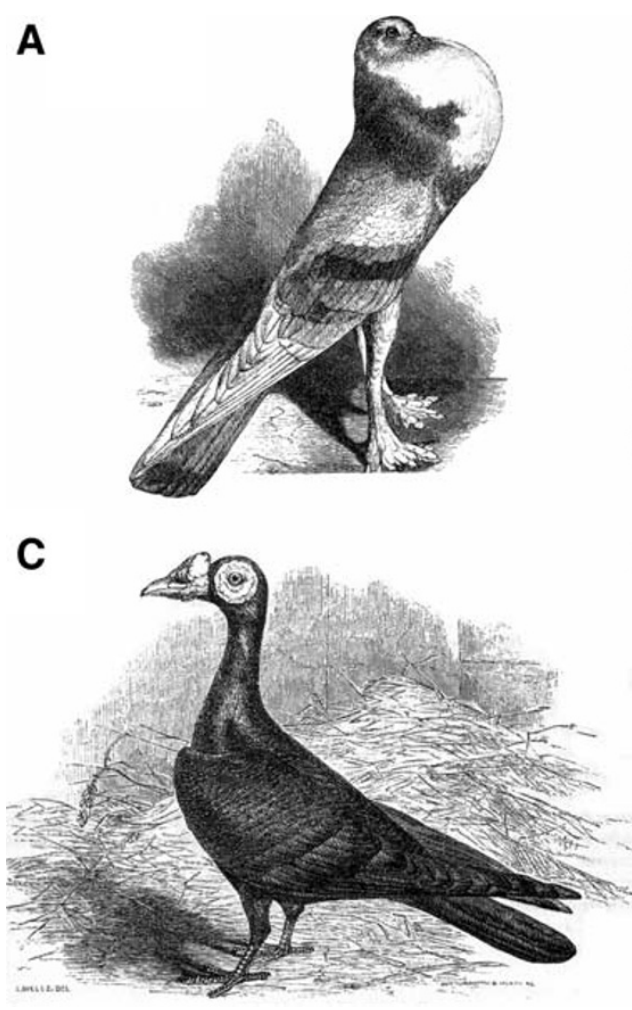

B

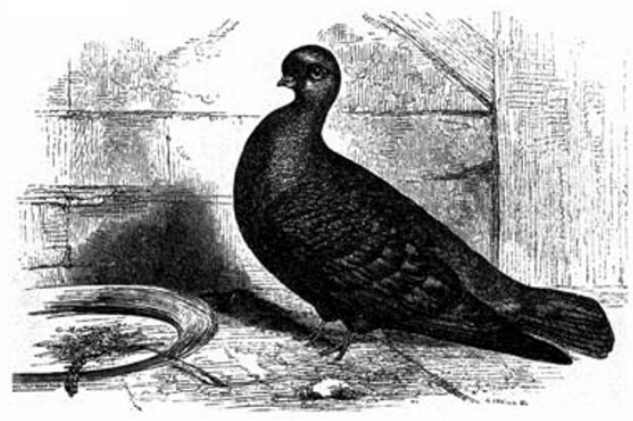

D

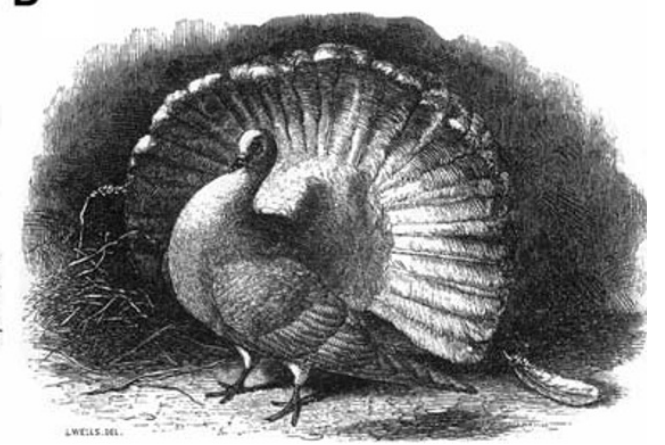

pastime, with fanciers seeking to produce new and dramatic varieties through diligently imposed artificial selection. Darwin was a member of pigeon fancier societies and even experimented with pigeon breeding himself, keeping up to 90 pigeons at a time at his home (Secord 1981). He marveled at the extraordinary variety of form produced by the methodical selection applied by skilled breeders (Fig. 1). In fact, artificial selection by pigeon fanciers had been so effective that Darwin (1859) noted,

"when I first kept pigeons and watched the several kinds, knowing well how true they bred, I felt truly as much difficulty in believing that they could ever have descended from a common parent, as any naturalist could in coming to a similar conclusion in regard to the many species of finches, or other large groups of birds, in nature."

Today, a (literally) more familiar example is provided by dogs (Canis lupus familiaris), several hundred distinct breeds of which have been generated. Domestic dogs display more morphological diversity than any other species of mammal, but most of these breeds have been produced within a few hundred years and all are derived from an early domesticated descendant of the gray wolf (Canis lupus lupus; Vilà et al. 1997; Savolainen et al. 2002).

Plants, too, have undergone substantial changes under the influence of prolonged artificial selection. As Doebley et al. (2006) noted, "most members of our modern industrial societies have never seen and would not recognize the unpromising wild plants that are the progenitors of our remarkably productive crops.” Beginning with the agricultural revolution around 10,000 years ago, hundreds of plants were domesticated on several continents (Fig. 2). However, nearly $70 \%$ of the calories consumed by humans derive from 15 species of plants-the top four of these being rice, wheat, maize (corn), and sugarcane (Ross-Ibarra et al. 2007). Many people are surprised to learn that these species, along with oats, barley, and sorghum, are all grasses in the family Poaceae. Of these, maize and rice have been particularly well studied in recent years, and a great deal of light has been shed on their evolution from wild grasses through artificial selection.

For example, it is now most commonly accepted that maize (Zea mays ssp. mays) is descended from the wild Mexican grass teosinte (Zea mays ssp. parviglumis) ${ }^{4}$. However, the morphological differences between maize and teosinte are so large that the hypothesis of their close affinity was rejected by many authors for decades after it was proposed (Wilkes 2004; Buckler and Stevens 2006; Fig. 3). Moreover, some authors argued that the differences between these plants were too drastic, and therefore the genetic underpinnings too complex, to have evolved in a straightforward way under domestication (see Wang et al. 2005). Indeed, teosinte was originally classified in the

\footnotetext{
${ }^{4}$ There are some authors who suggest that maize is a hybrid between Tripsacum and a perennial teosinte (e.g., Eubanks 2001), though many others consider this hypothesis implausible (Bennetzen et al. 2001; Emshwiller 2006).
} 

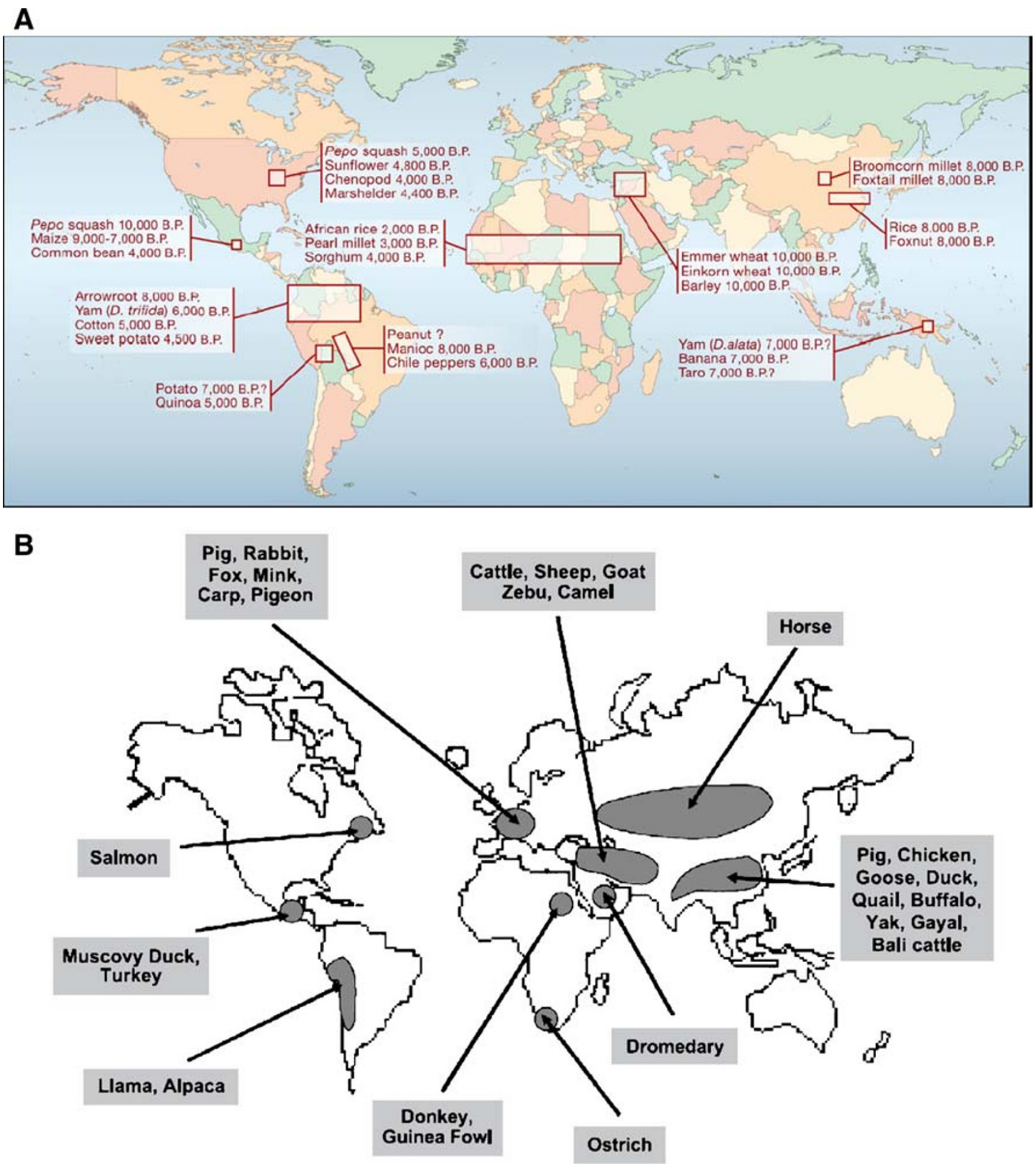

Fig. 2 Numerous sites of domestication have been identified based on archeological evidence for both a plants and $\mathbf{b}$ animals. a From Doebley et al. (2006) and b from Mignon-Grasteau et al. (2005), reproduced by permission of Elsevier and Dr. John Doebley

genus Euchlaena rather than with maize in the genus Zea (Buckler and Stevens 2006; Emshwiller 2006).

Maize, rice, wheat, and many other domesticated seed plants exhibit a common suite of features collectively known as the "domestication syndrome" (Harlan et al. 1973; Heiser 1988; Doebley et al. 2006; Zeder et al. 2006a; Ross-Ibarra et al. 2007). Depending on the species, this typically includes:

- Simultaneous ripening of seeds on the plant

- Loss of natural seed dispersal (no "shattering")

- Increased seed size

- No seed dormancy
- Compaction of seeds into highly visible "packages"

- Reduced seed coat thickness

- Simultaneous and rapid germination

- Synchronous flowering

- Reduced branching

- Gigantism

- Loss of toxic or unpleasant compounds (e.g., reduced bitterness) or other means of defense against herbivores

These novel characteristics greatly alter the means by which plants grow and reproduce. Yet, despite these major differences, most domesticated crops remain capable of 


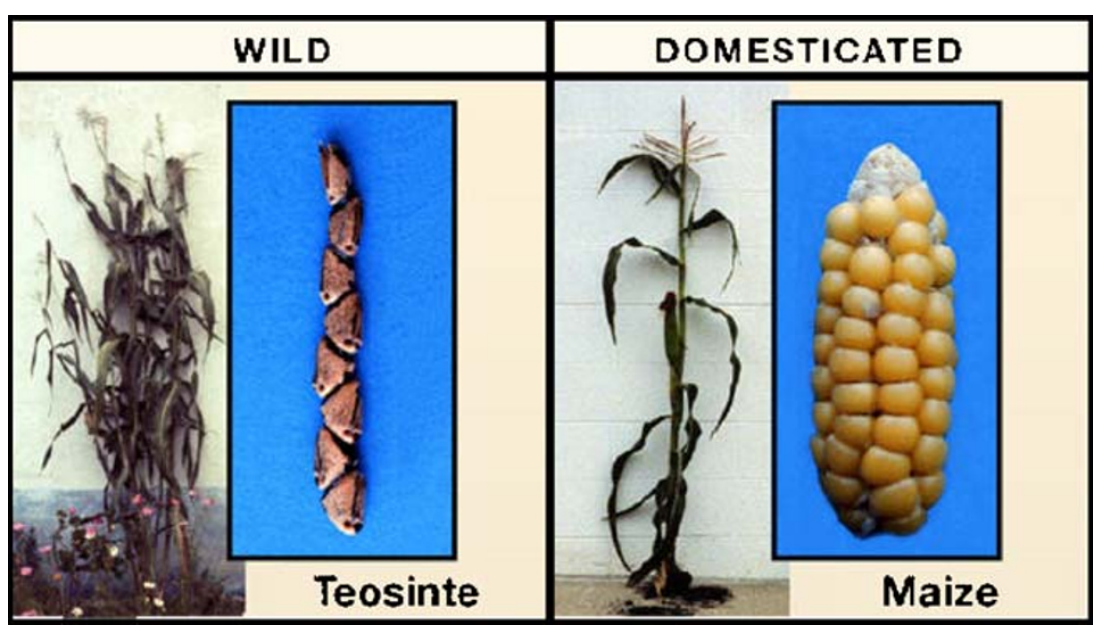

Fig. 3 A plant of the maize progenitor, teosinte (left), with multiple stalks and long branches, is shown next to a plant of cultivated maize $($ right) with its single stalk. A maize ear (inset) bears its grain naked on the surface of the ear, whereas a teosinte ear (inset) has its grain

intercrossing with their wild progenitors and at most represent distinct subspecies. In this regard, it could be argued (as it was by Wallace in 1858) that artificial selection differs fundamentally from natural selection. However, this is not always the case. Notably, modern bread wheat, Triticum aestivum, represents a separate hybrid species whose cells contain the genomes of three other species, some wild and some independently domesticated (Salamini et al. 2002; Motley 2006).

\section{Lesson 2: Unique Evolutionary Events}

Can Be Reconstructed Using Several Types of Data

There is no scientific debate as to whether domesticated animals and plants are descended from wild ancestors-i.e., this is accepted as historical fact (Gregory 2008a). The specific mechanism(s) involved in this transformationmost notably artificial selection-represents the theory proposed to explain the fact and also is generally agreed upon. Where there is often significant disagreement is in regard to the path of evolution under domestication: When did domestication take place? Where? From which ancestor? Once or multiple times for a particular species? Involving what historical sequence of changes? Under what cultural or environmental circumstances?

Such questions can almost never be answered with certainty because, a few examples notwithstanding (e.g., strawberries, pecans, sugar beets, rubber), most plants and animals were first domesticated long before the beginning of recorded history (Diamond 2002; Wilkes 2004). Obviously, no eyewitness testimony exists to detail the transformation of wild animals or plants into domesticates, and in any case the process has almost always been too gradual to have been noticeable on the timescale of an observer's (not visible) enclosed in the triangular casing that comprises the ear From Doebley et al. (2006), reproduced by permission of Elsevier and Dr. John Doebley

lifetime (see below). Nor is every intermediate stage preserved such that a step-by-step transition can be determined $^{5}$, and in many cases the wild progenitor is extinct. In this sense, the challenge of reconstructing the history of domestication is similar to that of studying natural evolutionary change over deep time. Darwin (18371838, Notebook B, p.217) used this fact to expose the absurdity of demands for a complete series of fossil intermediates before common descent is acknowledged: "Opponent will say: show them [to] me. I will answer yes, if you will show me every step between bull dog and greyhound."

Whether in reference to domestication or evolution at large, the challenge of reconstructing the past can be met by drawing careful inferences from diverse lines of evidence (Wilkes 2004; Zeder et al. 2006a, b; Burger et al. 2008). The primary lines of evidence used in the study of evolution by artificial selection are outlined below, and all have parallels with the approaches used in evolutionary biology generally.

\section{Comparative morphology}

One of the simplest means of investigating the historical relationships among living species is through a comparison of their physical characteristics. As a notable early example, Darwin (1868) compared the features of various breeds of pigeons and used this information to construct a diagram of their hypothetical relationships (Fig. 4). This represents one of the first attempts to reconstruct an evolutionary tree, or

\footnotetext{
${ }^{5}$ Some interesting partial exceptions exist, at least in terms of very recent examples of artificial selection. For instance, Drake and Klingenberg (2008) were able to use museum specimens to track the gradual changes in skull shape among dogs in the St. Bernard breed that occurred as a result of selective breeding over the past 120 years.
} 
COLUMBA LIVIA OR ROCK-PIGEON.

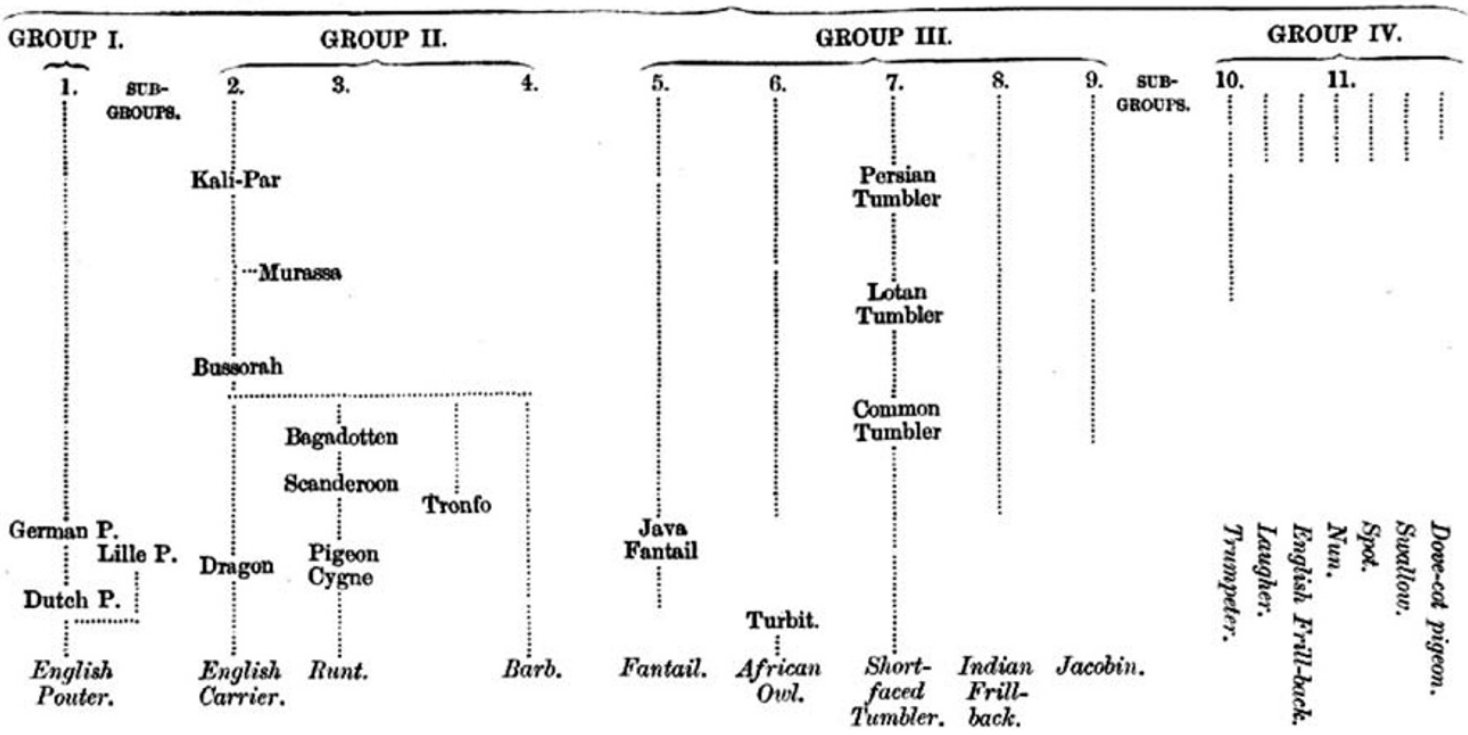

Fig. 4 Darwin's (1868) attempt to classify the various breeds of pigeons (Fig. 1) according to their physical characteristics and inferred historical relationships following their common descent from the wild rock pigeon (Columba livia)

phylogeny, through a comparison of living organisms (see Gregory 2008b). Similar analyses are often conducted in studies of domesticated animals and plants in order to indicate plausible ancestors and to suggest probable changes that were experienced during their evolution under artificial selection. However, as noted, the differences between domesticates and their ancestors can be profound, thereby confounding analyses based solely on morphological features.

\section{Geographical distribution and diversity}

In cases where a wild progenitor species is reasonably well established, one may use the approach pioneered by de Candolle and Vavilov of identifying the geographical region in which the progenitor is most common and in which its populations are the most diverse (see Wilkes 2004). This is often taken as an indication of the center of origin for domesticated species, though other types of data sometimes reveal the history of particular domesticates to be more complex than this method alone would imply (Wilkes 2004). Based on these and other data, it is now recognized that domestication has occurred independently and repeatedly in various parts of the world (Fig. 2).

\section{Archaeology}

The discovery of preserved prehistoric remains is important in the study of domestication (archeology), just as the fossil record is in the study of large-scale evolution (paleontology) (see Smith 2006). In some cases, intact remains of plants or animals can provide a clear indication not only of where early domestication took place but, thanks to radiometric dating and other techniques, also when. As an example, Piperno and Flannery (2001) reported the discovery of ancient maize cobs from Guilá Naquitz Cave (near Mitla, Oaxaca, Mexico) which dated to about 6,250 years ago (see also Benz 2001). A remarkable series of maize remains of increasingly recent ages reveals several of the transitions thought to have taken place between wild teosinte and the domesticated crop (Wilkes 2004).

As with the fossil record, intact specimens are less common than fragments or other sources of indirect information. In this case, archeologists may discover small remnants of plants that provide information about the time of origin of particular features. For example, wheat spikelets, which in living plants provide the points of attachment of stalk to seed-bearing ear, may be smooth at the site of detachment, meaning that they broke off easily as in wild plants (dehiscent), or may be jagged, indicating that threshing was required to remove the seeds, as with domesticated wheat (indehiscent) (Tanno and Willcox 2006; Balter 2007; Fig. 5). By examining the proportions of dehiscent to indehiscent spikelets from archeological samples, Tanno and Willcox (2006) were able to reconstruct the timing of the transition between wild and domesticated wheat.

In some cases, only microscopic remains are available, as with starch grains or phytoliths ("plant stones"; tiny silica particles formed in living cells of plants as protection from predators, reservoirs of carbon dioxide, and structural support). Both starch grains and phytoliths can be used to distinguish plant species and in some cases can indicate domesticated versus wild subspecies (Piperno et al. 2004; Smith 2006). Phytoliths, in particular, are inorganic and do 
Fig. 5 A summary of some of the major differences between a wild and $\mathbf{b}$ domesticated wheat, most notably the loss of shattering and larger seeds in the latter wheat. In wild wheat, shattering leaves behind a smooth scar at the point of attachment, whereas domesticated wheat requires threshing to remove seeds (making them easier to harvest), leaving behind a rough scar. From Salamini et al. (2002), reproduced by permission of Nature Publishing Group and Dr. Francesco Salamini, with inset photos of detachment scars from Tanno and Willcox (2006), reproduced by permission of the American Association for the Advancement of Science and Dr. George Willcox a Wild $T$. boeoticum

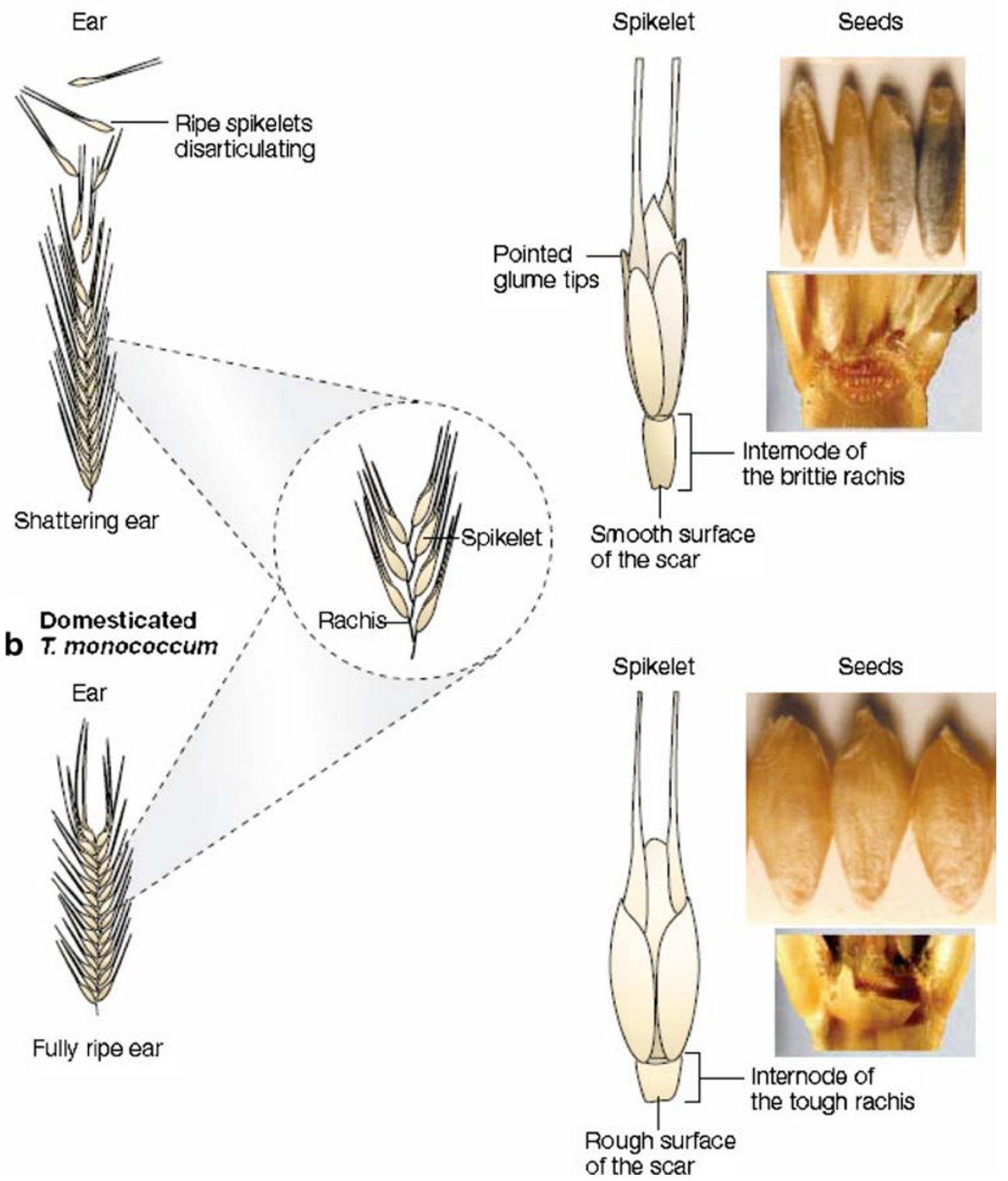

not readily decay, and their use in identifying the plant that produced them has been recognized since Darwin's time (e.g., Darwin 1846). In cases where starch grains or phytoliths do not by themselves provide positive identification of particular domesticated crops, the presence of samples from multiple cultivated plants in the same location can provide indirect evidence (Smith 2006; Thompson 2006). Finally, the presence of artifacts such as farm implements, grinding wheels, or cooking vessels used in association with domesticated plants can provide further means of identifying when and where early cultivation occurred.

\section{Chromosome data}

Some of the earliest genetic data used to assess relationships among crop plants and wild relatives involved analyses of chromosome number and morphology. For example, work in the 1930s made use of chromosome number information to support the proposed affinity between maize and wild teosinte. Beginning in the 1940s, chromosome comparisons revealed that specific characteristics such as the lengths of chromosome arms, the positions of centromeres, and the sizes and positions of unique features such as dense heterochromatic knobs are very similar in maize and Mexican teosintes but different from other proposed progenitor species (see Doebley 2004). Chromosome data continue to be of interest, especially in studies of hybrids in which multiple genomes are combined or genomes are duplicated. Today, this may involve sophisticated approaches for "painting" chromosomes with fluorescent probes to identify similar regions among species (e.g., Zhang et al. 2002). 


\section{Protein-coding nuclear genes}

The study of domestication, like that of evolution generally, has been revolutionized by the advent of molecular genetics. Some of the first means of assessing genetic variation within species of interest involved comparisons of enzyme variants (allozymes or isozymes) that differ slightly in physical properties and therefore can be separated using an electric current run through a gel (see Jones and Brown 2000; Emshwiller 2006). In addition, comparisons of sequences of the amino acids that make up proteins provided important insights into relationships among species. These techniques are still in use, but even more detailed information is now available through the analysis of DNA sequences. Not only can more general differences at the DNA level provide convincing evidence of historical links between domesticates and their wild relatives (e.g., Bruford et al. 2003) but, as described in more detail below, it is even becoming possible to identify the specific genes involved in the evolution of domesticated animals and plants.

\section{Non-coding DNA}

In most animals and plants, protein-coding genes make up only a small minority of the genome. Most DNA in these organisms takes the form of non-coding DNA of several types (Gregory 2005). Sequences such as microsatellites, which are highly repeated segments of DNA that are present in varying amounts among species and/or populations, can provide a sensitive marker for studying relationships among plants and animals (e.g., Bruford et al. 2003; Emshwiller 2006). Moreover, because non-coding sequences usually are not constrained in the same manner as functional protein-coding genes, they are often thought to evolve largely at random and can be used (with caution) as "molecular clocks" to infer the timing of divergences among lineages (Bromham and Penny 2003; Ho and Larson 2006).

Transposable elements, which are sequences capable of inserting copies of themselves in various locations in the genome, are particularly useful for inferring historical events (e.g., Kumar and Bennetzen 1999; Kumar and Hirochika 2001; Schulman et al. 2004a, b; Panaud 2008). These elements are often described as parasites of the genome because they reproduce themselves independently. Retrotransposons, in particular, are very abundant in animal and plant genomes and, like retroviruses, spread by being transcribed into RNA and then reinserting back into the DNA of the "host" chromosomes. These new copies remain incorporated in the host genome and are passed on to offspring, such that insertions can accumulate over time in lineages of plants and animals. By comparing the locations of transposable element insertions, it is possible to reconstruct the historical order in which species branched from common ancestors: species sharing many common insertions are more closely related and diverged more recently than those with only a few such shared insertions (see Shedlock and Okada 2000; Shedlock et al. 2004; Mansour 2008). This type of analysis has been used in reconstructing relationships among domesticated rice and its relatives, for example (Cheng et al. 2002; Xu et al. 2007). The same approach has been used to illustrate the close evolutionary ties between whales and even-toed ungulates (e.g., Nikaido et al. 1999, 2006) and to elucidate relationships among primates (e.g., Salem et al. 2003; Xing et al. 2005; Herke et al. 2007).

\section{Organelle DNA}

As the bodies of animals and plants function through the action of specialized organs, so the survival of individual animal and plants cells depends on the presence of subcellular organelles. Prominent among these are mitochondria, which are essential for cellular respiration in both animals and plants, and chloroplasts, which carry out photosynthesis in plants. Both mitochondria and chloroplasts are descendents of formerly free-living microorganisms ( $\alpha$-proteobacteria and cyanobacteria, respectively) that have become incorporated into host cells but continue to reproduce independently inside them. Though many of their genes have been lost or have migrated to the nucleus, these organelles retain their own genomes which evolve largely independently of the nuclear genome. Analyses of mitochondrial genes, in particular (and often in concert with microsatellite data), have proved very useful in disentangling the complex history of domestication of various animals (e.g., Savolainen et al. 2002; Bruford et al. 2003; Driscoll et al. 2007). Similarly, chloroplast DNA has long been used in the study of domesticated plants (e.g., Palmer 1985; Matsuoka et al. 2002; Wills and Burke 2006; Kawakami et al. 2007). Because they evolve largely independently of the nuclear genome, organelle genomes provide yet another source of genetic data for testing evolutionary hypotheses.

\section{Genomics}

Analyses of particular segments of DNA have only been used in force for studies of domestication since the early 1990s. The field advances so rapidly, however, that this already has expanded to include methods that focus on entire genomes. The technique known as amplified fragment length polymorphism analysis, for example, has undergone considerable advances since its emergence in the mid-1990s and is now often used in studies of domesticated species (Salamini et al. 2002; Meudt and Clarke 2007). This approach involves using enzymes to digest total genomic DNA, followed by selective amplification of fragments of mostly non-coding DNA from regions distributed throughout the genome (see Meudt and Clarke 2007). 
The most recent addition to the arsenal of evolutionary science is the ability to read the letter-by-letter sequence of entire genomes. A draft of the human genome sequence was published in 2001, and since then the field of comparative genomics has exploded to include dozens of animals, plants, and fungi (and hundreds of bacteria). Most of the eukaryote species sequenced to date have been chosen because of their importance as disease organisms or vectors (e.g., malaria, mosquitoes) or medical/biological research models (e.g., nematode worm, vinegar fly, mouse, rat, rhesus macaque). Domesticated species have been high-priority targets for genome sequencing as well. At the time of this writing, genome sequences are either published or under way for cat, dog, chicken, turkey, pig, cow, rabbit, horse, alpaca, honeybee, silkworm moth, rice, maize, wheat, barley, sorghum, oat, rye, soybean, tomato, potato, alfalfa, cauliflower, grape, orange, coffee, cocoa, cotton, banana, kidney bean, and manioc (Liolios et al. 2008; http://www.genomesonline.org). There is little doubt that the availability of complete genome sequence information from these and related species will provide unprecedented insights into the process of domestication through artificial selection.

\section{Ancient DNA}

Studies of genes from modern populations of domesticated animals and plants can reveal the genetic underpinnings of traits that were selected by early farmers (see below). These may also make it possible to evaluate some historical patterns of genetic change, but this cannot extend beyond statistical inference. Fortunately, direct insights about the genetics of ancestral animal and plant populations are becoming possible through the recovery of DNA from archeological material (see Brown 1999; Jones and Brown 2000; Bruford et al. 2003; Zeder et al. 2006a, b). In one recent example, Jaenicke-Després et al. (2003) retrieved ancient DNA from archeological maize cobs from Mexico and the southwestern United States ranging in age from 4,400 to 660 years ago. This allowed them to trace the increase in frequency of three gene variants (alleles) encoding features that were under selection during early maize domestication. Ancient DNA analyses have also been used in studies investigating the domestication history of animals, as for example in the recent work by Leonard et al. (2002) on dogs and of Larson et al. (2007) on pigs. Ancient DNA is coming to play a significant role in broader evolutionary studies as well. In some extraordinary cases, this involves not only the recovery of particular gene sequences but of entire genomes. Remarkable examples include the ongoing project to sequence the Neanderthal genome (Noonan et al. 2006) and the recent publication of the genome sequence of the extinct woolly mammoth (Miller et al. 2008).

\section{Data from other disciplines}

Evolutionary research is, by its nature, strongly interdisciplinary. This is no less true when the evolution under study is the result of artificial selection. Thus, the study of domestication has benefited from information derived from geology, paleoclimatology, physical and cultural anthropology, and even linguistics in order to identify the environmental and cultural contexts in which these transitions took place (e.g., Diamond 1997, 2002; Bellwood 2005).

\section{The Power of Consilience}

It is a simple truism that unique, irreproducible, prehistoric events cannot be known with absolute certainty. However, it is far from true that these cannot be inferred with great confidence. As the study of domesticated animals and plants shows, a wide range of independent lines of evidence can be brought to bear on such questions, made all the more powerful by their common convergence on similar answers. Domestication has been investigated using comparative morphology, biogeography, archeology, and numerous independent sources of genetic data ranging from chromosome number to gene sequences to complete genomes to ancient DNA. The rise of each new approach allows previous hypotheses to be tested and, where necessary, new ones to be postulated. For this reason, claims regarding evolutionary relationships between domesticates and wild species can be, and regularly are, tested empirically. No reliable observation has yet been made to refute the notion that livestock, pets, and crops evolved from wild predecessors. On the contrary, the details of when, where, and how this occurred are becoming increasingly clear. Where there is disagreement, it relates not to the fact of evolutionary descent but to specific points about the mechanisms, locations, or timing of change. All of these considerations apply in the study of evolution by natural selection as well.

\section{Lesson 3: Selection Requires Heritable Variation,} Which Arises by Chance

\section{The Hand of Nature}

There can be no selection, artificial or otherwise, if all individuals are the same or if the differences among individuals are not heritable. It is clear that Darwin recognized this fact, even though the mechanisms of inheritance were unknown to him. In the introduction to The Variation of Animals and Plants Under Domestication, Darwin (1868, p. 2) noted that, regardless of the intensity of artificial selection, "if organic beings had not possessed an inherent tendency to vary, man could have done nothing." In addition, Darwin understood well that selection itself 
does not cause variation and therefore that no severity of need or strength of preference can make beneficial traits appear. As he wrote (Darwin 1868, p. 3), "although man does not cause variability and cannot even prevent it, he can select, preserve, and accumulate the variations given to him by the hand of nature in any way which he chooses." Thus, the traits that come to be selected either already exist in a minority of individuals, arise by chance, or are introduced from outside through crossbreeding. Even methodical selection, Darwin realized, is dependent on variants that arise without regard to human desire. In this case, most changes that happen to occur will be considered neither positive nor negative and will simply be ignored. Of those changes that are visible, most are likely to be less desirable than the current standard-but on rare occasions, differences of interest will become available.

\section{Detecting Domestication in the DNA}

Domesticated animals and plants have played an important role throughout the history of genetics. Indeed, the term "gene" itself is derived indirectly from Darwin's (incorrect) theory of blending inheritance known as "pangenesis," which was presented in volume II of The Variation of Animals and Plants Under Domestication. A correct particulate theory of heredity likewise was developed using domesticated species, most notably in the famous crosses of pea plants performed by Gregor Mendel.

For more than 50 years, it has been known that genetic mutations - undirected errors at the DNA level - are responsible for generating the heritable variation among individuals upon which all other evolutionary processes rely. Nevertheless, and notwithstanding the strong historical link between genetics and domestication, the question of the specific genetic changes that have undergirded the domestication of animals and plants has only been the subject of intensive study since the early 1990s (Doebley 1992; Emshwiller 2006). Progress in elucidating the genetics of evolution under artificial selection has been remarkably swift, especially with regard to crops (e.g., Gepts 2004; Doebley et al. 2006; Ross-Ibarra et al. 2007; Burger et al. 2008). As Burger et al. (2008) noted recently with regard to crops,

These advances not only allow for an investigation of the overall genetic architecture of the wild-crop transition, but also make possible the identification of genomic regions and genes that were subjected to selection during the evolution of various crops. In some cases, researchers have been able to pinpoint the exact nucleotide changes responsible for the production of key crop-related traits.

Two major approaches have been taken to discovering genes involved in generating the domestication syndrome in crops, which Ross-Ibarra et al. (2007) categorize as either "top-down" or "bottom-up." The top-down approach involves observing phenotypic differences between crops and their wild progenitors and then performing tests to identify regions of the genome involved in producing them. Traditionally, this has included carrying out numerous crosses (either of inbred strains or of closely related species) and examining the patterns by which traits of interest segregate. By using molecular markers, specific features of known genomic location, it is possible to map the location of regions linked to the appearance of particular phenotypic traits. These are known as quantitative trait loci (QTLs) and may be genes, regulatory regions, or other elements linked to genes involved in producing particular characteristics (see Collard et al. 2005). Methods developed in mammalian genetics, such as linkage disequilibrium mapping, also have been applied recently in the detection of relevant genes among crops (Mackay and Powell 2006; Ross-Ibarra et al. 2007). Once identified, genetic loci associated with particular traits can then be further analyzed by DNA sequencing and compared with other known genes to determine their precise roles.

The bottom-up approach, by contrast, begins with analyses aimed at detecting regions in the genome that have been under selection and then seeks to determine the phenotype with which they may be associated. This can be accomplished by examining a large sample of plants and assessing the amount of diversity among them at particular genetic loci. Because selection involves allowing only a subset of each population to reproduce, it has the effect of reducing total genetic variation-sometimes severely (e.g., Haudry et al. 2007). However, the "bottleneck" effect of selection is not exerted uniformly in the genome: regions associated with traits under selection will be particularly strongly affected and therefore will exhibit especially low diversity in modern populations compared to "neutral" genes not under selection (Ross-Ibarra et al. 2007; Fig. 6). Another approach involves scanning the genome for sequences that show signs of having been under selection (see Wright and Gaut 2005; Nielsen et al. 2005). Once such regions have been identified, the next step is to investigate their phenotypic impacts, for example by experimentally disrupting their function and observing the consequences (Vollbrecht and Sigmon 2005; Doebley et al. 2006).

\section{Recent Discoveries in Cereal Crops}

Using the approaches outlined above, biologists have made a number of recent discoveries that highlight the ways in which random mutation and artificial selection have generated profound changes in domesticated animals and plants. Some notable recent examples from cereal crops are outlined in the following sections. 


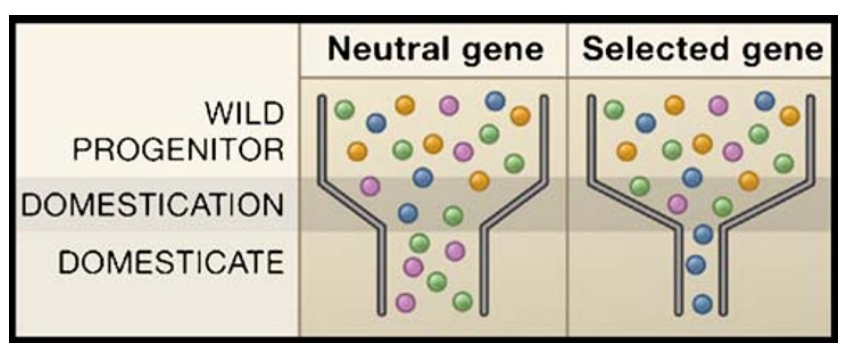

Fig. 6 Domestication results in a genetic bottleneck for genes under selection (right) as well as neutral genes that are not under selection $(l e f t)$. In this figure, the different shades of balls represent genetic diversity, with more significant loss of diversity occurring in genes under selection. This can be used to detect genes that have been involved in domestication, although it should be borne in mind that severe bottlenecks may greatly reduce variation in neutral genes as well and thereby make it difficult to determine which genes have been under selection. From Doebley et al. (2006), reproduced by permission of Elsevier and Dr. John Doebley

\section{Maize: turning teosinte inside out}

Maize is unique among crops in the dramatic physical differences that separate it from its wild ancestor, in particular with regard to the structure of the ear (i.e., the seed-bearing female inflorescence). In teosinte, the ears are composed of multiple stalks, each of which includes five to 12 kernels. Teosinte kernels fall separately to the ground when mature and are enclosed within a hard stony fruit case made up of a cupule in which the kernel sits and a glume that covers the cupule opening. These fruit cases are sufficiently strong to survive passage through the digestive system of an animal. Maize ears, in stark contrast, are single-stalked and may possess 500 or more kernels arranged into 20 or more rows. More significantly, the kernels of maize are naked (i.e., lack a hard case) and remain firmly attached to a central cob when mature (Doebley 2004; Buckler and Stevens 2006; Fig. 3). In light of such major differences, it was argued that too many genetic changes would be required to convert teosinte into maize in less than 10,000 years (see Doebley 2004; Wang et al. 2005). Yet, it was soon shown that maize remains genetically similar enough to its wild relatives that the two subspecies may readily be crossed (Doebley 2004). Therefore, reconciling the extreme morphological disparity but close genetic similarity between maize and teosinte became an important objective for understanding maize evolution.

The first major insight along these lines came in the early 1970s when George Beadle crossed maize and teosinte and categorized 50,000 descendant plants as having ears identical to teosinte, identical to maize, or intermediate between them. He found that the frequencies of teosinte and maize ears both were roughly one in 500, from which it was concluded that around five genes of large effect could have underlain the evolution of primitive maize, with various additional genes later providing more modest input (see Doebley 2004; Buckler and Stevens 2006). These data arrived several decades after the teosinte hypothesis was proposed, and it took another 20 years before specific candidate genes were identified. Thanks to modern molecular analyses, insights have begun to accumulate rapidly (e.g., see reviews by Doebley 2004; Pozzi et al. 2004; Buckler and Stevens 2006; Doebley et al. 2006).

The kernels of maize are not enclosed within a stony fruit case, but cupules and glumes are still present: they form the central cob to which the kernels are attached. As Wang et al. (2005) put it, "In a sense, maize domestication involved turning the teosinte ear inside out." A QTL known as teosinte glume architecture 1 (tgal) has been identified as playing an important role in this transition (Doebley 2004). Tgal may represent one gene or several linked genes. However, it has been established that the difference between teosinte and maize alleles involves as few as 7-bp substitutions which result in a single amino acid change that may impact regulatory function (Wang et al. 2005). Though minor at the genetic level, these changes result in a substantial morphological effect, namely the loss of fruit cases around grains (Fig. 3).

Another QTL of major effect known as teosinte branched $1(t b l)$ has been found to result in maize with one stalk rather than the more highly branched form found in teosinte. This gene(s) is part of a family of regulatory genes known as TCP transcriptional regulators which influence the expression of other genes involved in regulating the cell cycle. It is thought that $t b 1$ represses cell division and prevents the outgrowth of additional branches, leading to single stalks tipped by ears (Doebley 2004; Doebley et al. 2006). Once again, this may represent a relatively minor genetic alteration, but one that exerts substantial impacts through its role in regulating plant development.

Many other genes of smaller effect are expected to have influenced features such as the size of the ear, growth conditions, and the nutrient content of kernels. More specifically, a scan of portions of the maize genome provided an estimate that $2-4 \%$ of genes have experienced artificial selection (Wright et al. 2005). Several candidate genes have already been identified (Wright et al. 2005), with some especially notable examples relating to kernel nutrient content. For example, a gene encoding prolamin box binding factor $(p b f)$ regulates the storage of proteins in maize while a gene known as sugaryl (sul) encodes enzymes involved in the storage of starch (Whitt et al. 2002; Jaenicke-Després et al. 2003). Sweet corn results from naturally occurring recessive mutations that may include the sugary (su), sugar enhanced (se), or shrunken $(s h 2)$ genes which control the conversion of starch into sugar in the endosperm of kernels. Another kernel nutrient gene, yellow $1(y 1)$, encodes an enzyme that produces yellow kernels with high-level carotenoids, a precursor for 
vitamin A synthesis (Palaisa et al. 2003). In this case, the difference relates to a change in a promoter sequence such that this gene is expressed in kernels and not just in leaves where it usually is activated. This gene is of interest because it has been under intense recent selection: when it was discovered in the 1930s that yellow corn is more nutritious for farm animals, almost all corn production in the US switched from white varieties to yellow (Doebley et al. 2006).

\section{Rice: a shatter-proof weed}

The grasses Oryza rufipogon and Oryza sativa are morphologically similar, closely related genetically, and capable of interbreeding - in fact, $O$. sativa is thought to be descended from $O$. rufipogon (or the annual form thereof, sometimes known as Oryza nivara; Sweeney and McCouch 2007). However, there is a major distinction between them: $O$. rufipogon is listed as a noxious weed in the United States whereas $O$. sativa (domesticated rice) is the primary source of nourishment for one third of the world's population. Interestingly, this extreme disparity in impact between the domesticated crop and its wild progenitor is derived from differences in some relatively simple features. Most notably, $O$. rufipogon produces seeds that fall from the plant (or "shatter"), which contributes to its weedy ability to disperse widely and makes it difficult to harvest ${ }^{6}$. Farmed rice, by contrast, exhibits the characteristics typical of the domestication syndrome, including a loss of shattering such that its mature seeds remain attached and are readily harvested. Indeed, shattering remains a major source of crop loss when it occurs and is a feature still under selection in modern breeding programs (Lin et al. 2007).

As with several features central to the domestication of maize, the loss of shattering in rice appears to be controlled by a small number of genes. In 2006, two independent research groups reported the existence of genes involved in this critical transition. First, Li et al. (2006) identified a QTL dubbed shattering4 (sh4) that exists in a dominant form in the wild species and controls the majority of the variance in shattering in crosses of wild and cultivated rice. The QTL maps to a region about 1,700 bp in length and, in the domesticated form, involves a single amino acid change that reduces but does not eliminate shattering. This makes it possible to harvest the grains but not impossible to remove them from the stalk (Doebley 2006; Doebley et al. 2006). Second, Konishi et al. (2006) identified another genomic region in crosses of the two subspecies of domesticated rice (japonica and indica) named QTL of seed shattering in

\footnotetext{
${ }^{6}$ O. rufipogon can be harvested (and still is in India), for example, by twisting plants together to prevent its seeds from falling to the ground. This added difficulty makes it clear why mutant plants with reduced shattering would have been selected for unconsciously by early farmers. See Vaughan et al. (2008).
}

chromosome 1 ( $q$ SH1) which involves a single base pair change $(G$ to $T)$ in a regulatory region that prevents expression of the gene at the site where seeds break free (the abscission layer) but which does not render it nonfunctional in other tissues. More recently, Lin et al. (2007) discovered another gene on chromosome 4, shattering 1 (shal), which also plays a role in eliminating shattering in domesticated rice and, as with $q S H 1$, involves a single nucleotide substitution (also $\mathrm{G}$ to $\mathrm{T}$ ) in a regulatory region.

Overall, at least five genetic loci are involved in the loss of shattering, while another six have been implicated in the loss of seed dormancy, another factor critical in the initial domestication of rice (Kovach et al. 2007). Dozens of additional genes of smaller effect recently have been recognized to influence features such as grain size, shape, number, color, and nutrient content, as well as other traits relating to growth and reproductive mode in rice (Kovach et al. 2007). Examples include: grain size3 (GS3), which influences grain length and weight (Fan et al. 2006); grain incomplete filling1 (gifl), which affects grain weight (Wang et al. 2008); grain numberl (Gnla), which contributes to higher yield (Ashikari et al. 2005); red pericarp ( $r c$ ), which determines seed color (Sweeney et al. 2006); waxy, which specifies amylose content and is important in sticky rice (Olsen et al. 2006); prostrate growth 1 (prog1), which reduces the number of extra stems or "tillers" (Jin et al. 2008); and two genes (including $f g r$ ) that relate to fragrance (Bradbury et al. 2005; Fitzgerald et al. 2008).

\section{Genetic Generalities}

The list of genes recognized to have played a role in early domestication and subsequent improvement of crops is growing rapidly. While it is too early to draw detailed conclusions, some general patterns are emerging. First, it can be seen that many of the major early transitions involved a small number of minor genetic changes with large phenotypic effects, for example mutations in regulatory elements and developmental control genes. Second, many of the subsequent improvements or variety-level differences that have evolved relate to larger numbers of small-scale mutations. Third, whereas many of the features that distinguish varieties are based on loss-of-function mutations, this clearly is not always the case. In fact, as far as is known, the genes of major effect at the heart of domestication in many species are functional (Doebley 2006; Doebley et al. 2006; Burger et al. 2008).

Lesson 4: Selection Is a Population-Level Process that Occurs over Many Generations

Identifying mutations that have played a key role in domestication is an important step in understanding how 
such remarkable transformations have taken place. It also raises an important question regarding the source of variation upon which early artificial selection depended: were these fortuitous new mutations that arose shortly before and/or sequentially during domestication, or were they already present in wild populations? In some cases, wild progenitor populations appear to be devoid of the alleles that determine the features of crops, as is the case with loss of shattering in rice or loss of the seed casing in maize (Doebley et al. 2006). In other cases, mutant genes important in domestication can still be found at low frequencies in wild populations, as has been reported for alleles affecting fruit size in tomato and plant structure in maize (Doebley et al. 2006). Some authors have suggested that it was not new mutations per se that resulted in the unique phenotype of maize but selection on standing variation and the bringing together of several rare variants for the first time (e.g., Vollbrecht and Sigmon 2005; Doebley et al. 2006). In any case, it is well recognized that populations of some wild progenitors, such as teosinte, exhibit remarkable levels of standing genetic variation, supplying ample raw material for the operation of artificial selection (e.g., Doebley 2004; Buckler and Stevens 2006).

Whether they were based on a series of new mutations or combinations of preexisting alleles, it is very likely that the key traits favored by early farmers initially would have been present in very low numbers within wild populations. This is especially probable given that many of the gene variants important in early domestication (e.g., reduced shattering, loss of seed cases) make their possessors less able to propagate on their own. Artificial selection explains how these rare variants became ubiquitous ("fixed") within modern domesticated populations. Unfortunately, the mechanism of selection is often misunderstood, and clarifying this process with the familiar example of domestication can provide useful means of improving the understanding of larger-scale evolution through natural selection. In this regard, some important points about the operation of artificial selection are outlined in the following sections.

\section{Domestication occurs over many generations}

The notion of an "agricultural revolution" may sometimes be taken to imply a rapid switch from hunter-gatherer lifestyles to one based on crop production. And indeed, within the span of human history, this was a comparatively brisk transition. However, on the scale of individual human lifetimes, it may have been so gradual as to be nearly imperceptible. As Kovach et al. (2007) put it, "domestication is not a single 'event' but rather a dynamic evolutionary process that occurs over time and, in some species, continues to this day." It is quite possible that a predomestication period of harvesting extended back 20,000 years for some species (Allaby et al. 2008). This is supported by evidence from microfossils and starch grains embedded in stones which indicates that cereals were being used millennia before evidence of major morphological changes arose (Zeder et al. 2006b).

There is increasing evidence that the process of domestication itself occurred over the span of a great many generations of plants (and farmers). Even transitions considered "fast" would involve 100-200 generations of plants (Gepts 2004), and there are growing indications that most processes have been nowhere near this rapid. For example, archeological evidence shows that corn cob form was under selection for thousands of years, and ancient DNA evidence indicates that even genes of large effect were present in maize at least 4,400 years ago but still were not fixed by 2,000 years ago (Jaenicke-Després et al. 2003). Similarly, archeological collections of wheat spikelets show that early populations contained both wild and non-shattering forms. Despite the substantial benefit provided by non-shattering ears, the process of fixation of this trait was drawn out over a millennium (Tanno and Willcox 2006; Balter 2007). Such a protracted rate of change under artificial selection appears to be typical among cereal crops, with changes in grain size taking $500-1,000$ years and alleles for loss of shattering becoming fixed after another 1,000-2,000 years (Fuller 2007).

It has been suggested that this surprisingly slow pace of change could have resulted because selection by humans was relatively weak (Fuller 2007) or because early farmers supplemented their seed stocks with wild varieties during lean years (Tanno and Willcox 2006). However, even under intense and uninterrupted selection, the process of changing allele frequencies in entire populations takes time. As an interesting illustration of this, crop domestication researcher John Doebley has initiated an experiment he dubs the "Redomestication Project" (http://teosinte.wisc. edu/redomestication.html):

How long did it take ancient peoples to domesticate maize from teosinte? We don't know the answer to this question and will likely never have a very precise answer, but there are ways we can make an educated guess to this and related questions. With this thought in mind, I began a "long term" selection study with teosinte (Zea mays ssp. parviglumis) to see if I can change the population to be more maize-like, i.e. to "redomesticate" maize. This study involves growing a large number of teosinte plants each year and harvesting seed from the most maize-like individuals for the next generation. I hope to continue this process for 30 generations.

Even with selection carried out in a controlled manner by an expert researcher, the prospects for change during the 
span of a human lifetime are modest. As Doebley writes on the project website (accessed Dec. 2008),

Over the next 28 years (the funding gods agreeable), I will grow out about 3000 seed of the selected progeny from the preceding generation and select the shortbranch plants...

I don't anticipate that this selection experiment will actually produce a maize replica. The plants should become more maize-like for branch length (and perhaps seed size and tillering), but for most other traits they should remain true to the teosinte condition. There is a chance that some other correlated traits such as the number of fruitcases per ear may change.

Doebley's experiment is also important in demonstrating the fact that traits may be selected individually (though often with correlated implications) and that selection is simply a matter of preserving and propagating variants with a slightly more favorable trait from one generation to the next, not of finding a fully domesticated plant hidden within a field of wild relatives. It also demonstrates that selection is not a process that occurred only in the distant past but also can be observed in the present.

\section{Individual organisms do not evolve}

In order to understand the process of artificial selection (and by extension, both domestication and natural selection), it is critical to bear two additional points in mind. First, features acquired by an individual organism during its lifetime are not passed on to offspring. The source of new variation in the next generation is mutation occurring in the germ of parents. Second, the undirected generation of heritable variation by mutation and the subsequent nonrandom sorting of variants by selection are two independent processes. This means that no matter how intense the selection pressure imposed by breeders may be, it will not cause specific favorable mutations to occur. Therefore, evolution is not a process in which individual organisms change in response to pressures from the environment (which may include choosy farmers). Rather, selection involves change in the average properties of the entire population as a non-random subset of each generation producing the next generation. In other words, individuals do not evolve, populations do.

\section{Selection is most effective in large populations}

As Darwin (1859) and Wallace (1889) both recognized, artificial selection is likely to be most effective in large populations. This is true for three major reasons. First, favorable mutations are rare, and having more animals or plants reproducing in the population provides more oppor- tunities for them to occur. Darwin described this explicitly in the Origin (Darwin 1859, p.40-41):

A high degree of variability is obviously favourable, as freely giving the materials for selection to work on; not that mere individual differences are not amply sufficient, with extreme care, to allow of the accumulation of a large amount of modification in almost any desired direction. But as variations manifestly useful or pleasing to man appear only occasionally, the chance of their appearance will be much increased by a large number of individuals being kept; and hence this comes to be of the highest importance to success.

Second, the chance of losing a favorable mutation due to chance by the process known as genetic drift is much higher when the population is small. Third, larger populations tend to be more variable and to be less affected by the loss of genetic diversity through domestication bottlenecks (Eyre-Walker et al. 1998; Doebley et al. 2006).

Using genetic data, it is possible to infer some information regarding the sizes of ancestral populations for domesticated animals and plants. In maize, for example, conservative estimates suggest an initial teosinte population size of 500 to 4,000 individual plants. Biologically speaking, this is a small population, but it is very different from simply picking between a few different plants. As cultivation increased, so too did the population sizes of the plants. Today, the number of maize plants cultivated is enormous given the ubiquity of this crop in processed food, livestock production, and a range of other industries (see Jahren and Kraft 2008). Wilkes (2004) suggested that "it takes 25 corn plants per person per day to support the American way of life." In another assessment, Buckler and Stevens (2006) pointed out that "if 10 people derive $10 \%$ of their calories from maize, it is estimated that roughly $250,000-350,000$ plants would have to be grown annually."

\section{Lesson 5: Adaptation Builds on What Is Already Present}

With the advent of genetic engineering, it has now become possible to add specific characteristics to crops and livestock at will, including by transplanting genes for desirable traits from other species. Traditional approaches based on selective cultivation or breeding, on the other hand, are more indirect and typically involve modifications of genes and physical features that are already present rather than the addition of fundamentally new characteristics. This process of altering existing features rather than redesigning from scratch - commonly called "tinkering"is a hallmark of evolutionary adaptation (for review, see Gregory 2008c). In maize, for example, the cob is formed from modifications of the cupule and glume, which in wild teosinte form the seed case (Wang et al. 2005). In other 
cases, different parts of the plant may be modified in very different ways. Notably, selective breeding in the wild cabbage species Brassica oleracea has produced a wide variety of distinct cultivars, each representing a modification of a particular part of the plant (Purugganan et al. 2000; Fig. 7). As Doebley (2006) aptly remarked, “Tinkering... is the order of the day in domestication as in natural selection and Darwin's use of domestication as a proxy for evolution under natural selection was, not surprisingly, right on the mark."

Lesson 6: What Matters Is Reproductive Success, Not Survival Per se

Domesticated animals and plants depend on humans in order to survive and/or reproduce. As a result, they are illsuited to life in the wild and would be at a severe disadvantage if forced to compete with wild relatives. However, under the conditions that they actually facenamely those created by humans - it is the domesticated forms that have been the most successful, by definition. In this sense, artificial selection provides an excellent illustration of a crucial point: selection is not about survival per se but about reproductive success. Thus, the phrase "survival of the fittest," which was coined by Herbert Spencer (a contemporary of Darwin's), is misleading if it implies physical fitness or other measures of survival ability. "Fitness" in the evolutionary sense is usually defined specifically in terms of reproductive success (e.g., Futuyma
2005), and survival is only relevant insofar as it contributes to enhanced reproduction. Put another way, regardless of how well an individual survives in its environment, it will not be evolutionarily fit unless its traits are actually passed on to the next generation.

If an individual possesses a heritable trait that, for whatever reason, results in its leaving more offspring than individuals lacking the trait, then that trait will become proportionately more common in the next generation. In terms of artificial selection, the traits that lead to greater relative reproductive success may be physiological, developmental, biochemical, or behavioral and may in fact be based on little more than human whim. But if the result is that individuals bearing them are statistically more successful in passing on their traits, then these will increase in frequency under artificial selection. Whether adapting to the new human-imposed environment made the plants dependent on farmers is irrelevant to considerations of what constitutes "fit"- dependency can also evolve under natural selection, for example among parasites or endosymbionts and their hosts. Therefore, criticisms of Darwin's analogy based on the fact that domesticated species are "less fit" in the wild (e.g., Richards 1997) are misplaced.

\section{Lesson 7: What Is Fit Today May Not Be Fit Tomorrow}

For most of their history, the species from which domesticated forms are derived evolved under pressures related to survival and reproduction in the wild. This includes
Fig. 7 An example of the modification of existing structures through artificial selection. (a) Wild Brassica oleracea, from which various domesticated cultivars have been produced based on changes to specific plant parts: $(b)$ broccoli (and cauliflower; flower clusters), (c) cabbage (leaves), (d) kale (leaves), (e) Brussels sprouts (leaf buds), and ( $f$ ) kohlrabi (stems). All images from Wikipedia

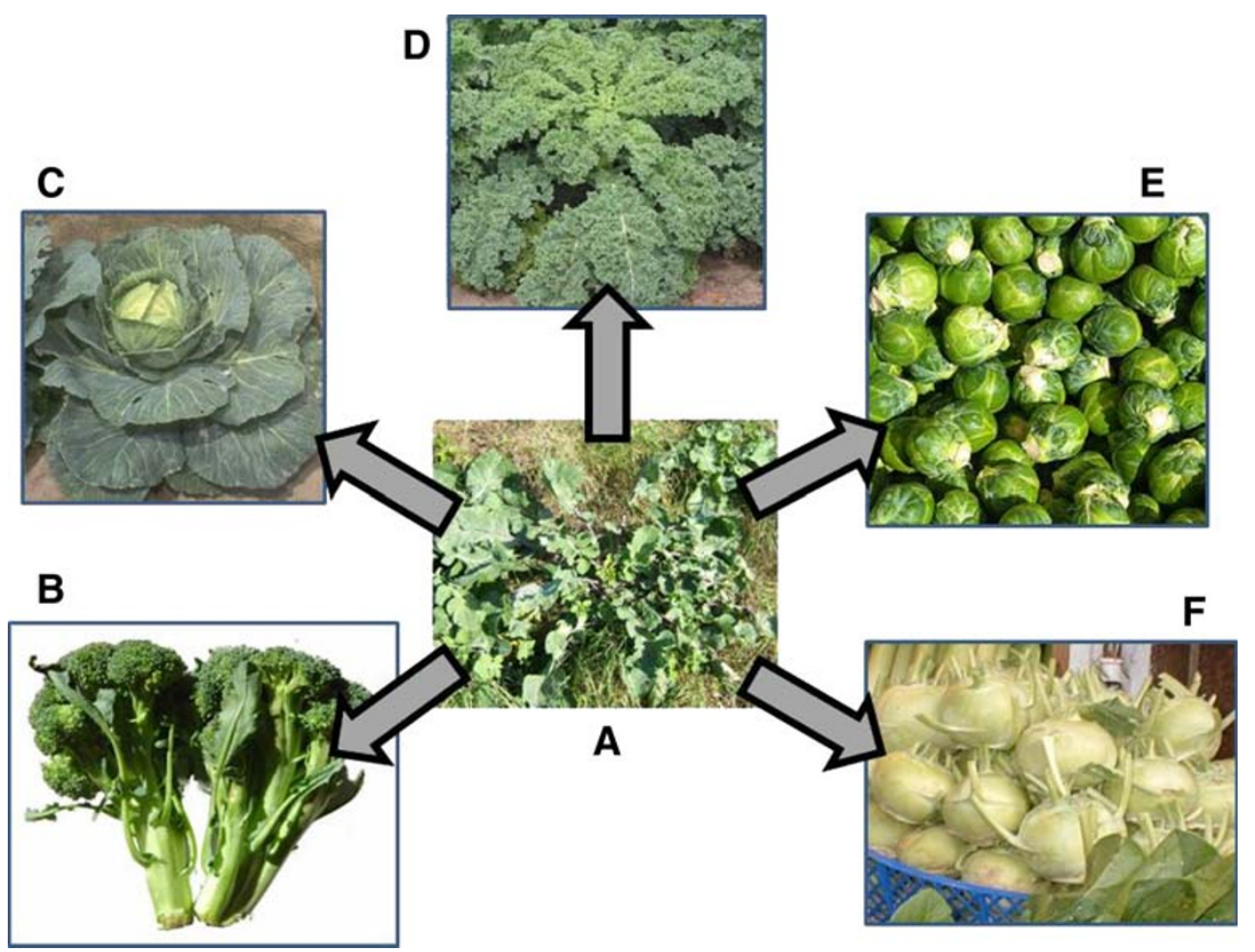


requirements for obtaining nutrients, avoiding being eaten, and reproducing successfully by dispersing seeds or acquiring mates. Through the non-random survival and reproduction of individuals from one generation to the next (i.e., natural selection), these plants and animals have become adapted to their particular environments. When early farmers began cultivating or raising these plants and animals, the traits that equated with higher fitness changed dramatically. Individual plants that were less able to disperse their seeds, that were less well protected against herbivory, and that invested more energy in features of interest to farmers (e.g., more sugar and starch in seeds) were the ones whose traits were passed on more frequently. Similarly, animals that were less aggressive and easier to manage were those that ultimately passed on their genes at the highest rate.

Changes in selective pressures, which sometimes may be dramatic, have played an important role in the evolution of life at large and help to explain its enormous diversity. From the perspective of the animals and plants under artificial selection, the arrival of humans and the imposition of their preferences in determining reproductive success are just another example of this.

\section{Lesson 8: Selection Can Lead to Either Divergence or Stability}

Though domestication is often described as a transformation of wild species into forms that are suitable for, and dependent on, human cultivation, it is generally not the case that the entire progenitor has been transformed. Rather, domestication involves changing a subset of the original species; in several species, domesticated populations and wild populations both continue to exist (Doebley et al. 2006; Tanno and Willcox 2006; Vaughan et al. 2008) (In this case, it must be noted that both domesticated and modern wild populations are descendants of an ancestral wild population such that this represents a case of divergence of one form into two (Emshwiller 2006) ${ }^{7}$. For this reason, it is no less misguided to ask "why are there still populations of teosinte now that domesticated maize has evolved?" than "why are there still apes now that humans have evolved?"; Gregory 2008b). The primary cause of this divergence has been the existence of differing selective pressures: in undomesticated forms, these remain pressures related to survival and reproduction in the wild, whereas in cultivated forms the pressures are imposed by farmers. Similarly, differing selective pressures applied to domesticated animals and plants can lead to divergence in the form of cultivars or breeds.

\footnotetext{
${ }^{7}$ The transformation of one entire species into another is known as "anagenesis" whereas branching from a common ancestor to form two or more species is called "cladogenesis."
}

Darwin recognized the role that differing selective pressures would play in creating biological diversity by identifying the "principle of divergence." The principle of divergence clearly applies in the case of methodical selection (Sterrett 2002), in which breeders develop very different forms according to their particular preferences (Fig. 1). However, once a specific breed has been established, the process of selective breeding becomes one of choosing individuals that conform most closely to recognized standards. In this case, mutations that cause deviation away from the current form are selected against, with the net effect of preventing further change. Both "directional selection" (pressure favoring one extreme and leading to change) and "stabilizing selection" or "purifying selection" (pressure preventing change away from the current state) are common in nature, and so once again artificial selection provides a clear example of an important general principle.

\section{Lesson 9: Selection Is Neither an Unlimited nor an Exclusive Mechanism}

In light of the extensive change that has been brought about in many domesticated species, it may be tempting to assume that all features of domesticates are the product of artificial selection and that the potential influence of this process is effectively limitless. There are several reasons why neither supposition would be correct.

\section{The Power of Selection Is Not Unlimited}

As Darwin (1868) recognized, without heritable variation with which to work, even the choosiest breeder or most diligent farmer would be powerless to effect change. Thus, one of the most obvious limitations of the power of selection is the dependence of the process on mutations that arise by chance. If relevant mutations simply never occur, then particular avenues of adaptive change will remain inaccessible.

The availability of mutations is just one of many factors, some internal and some external, that can determine-or block - the path to domestication in different species. Indeed, it is clear that certain groups of animals and plants are far less amenable to domestication than others (Diamond 1997, 2002; Gepts 2004; Zeder et al. 2006b). Intrinsic factors such as the amount of crossbreeding (i.e., transfer of genes among populations or "gene flow"), reproductive mode (e.g., propensity for self-fertilization in plants), generation time, tolerance of new environments, and genetic characteristics may all make it more or less likely that particular species will respond to artificial selection. External factors such as climate, soil conditions, water availability, and other features may similarly dictate 
which regions are likely to serve as cradles of domestication (Balter 2007; Allaby et al. 2008). Even among those species that are domesticated, these intrinsic and extrinsic factors may affect how rapidly (or how many times) the process occurs.

Sometimes, the prospects for domestication can depend on the probability of major genetic changes (such as genome duplications and/or hybridizations, as in polyploid wheat), but it also may be as simple as the nature of the genetic system underlying specific features. As an interesting example of this, Diamond (2002) considers why almonds were domesticated but other trees such as oak were not. Both almonds and acorns are bitter and toxic in the wild, but domesticated almonds have been selected for a loss of toxicity. Acorns have traditionally been an important wild food source for foragers, and occasional non-toxic trees do arise and are preferred. However, whereas almond toxicity is controlled by one gene such that mutant plants provide offspring that are also non-toxic, toxicity in oak is determined by multiple genes, meaning that offspring of nonpoisonous oaks are rarely non-poisonous themselves. This difference in genetic system, and its associated consequences for the reliability of breeding outcomes, may explain why almonds and not acorns are widely cultivated.

\section{Adaptation Comes with Tradeoffs}

While it is possible to select among individuals on the basis of particular traits, it is nonetheless the case that organisms are integrated entities whose parts are functionally interconnected. In addition, a finite number of resources is available for the construction of an adult animal or plant, meaning that not all parts can be accentuated indefinitely without compromising the function of other parts. The consequences of these facts are known as "tradeoffs."

Tradeoffs have played an important role in domestication, just as they do in other examples of adaptation. As a notable example, selection for higher yield often comes at a cost of lower protein content per seed among cereal crops: domestic grains may exhibit only $50 \%$ of the protein content of those of their wild relatives (Doebley et al. 2006). Moreover, the production of plants with larger, more flavorful grains may require more water or nutrients to produce, may grow more slowly, and may become host to new insect pests, thereby necessitating a significant investment of human labor for their cultivation. Similarly, selection for more rapid growth has had the consequence of drawing resources away from features such as brain size and acuity of sense organs in domesticated animals (Diamond 2002).

Tradeoffs may also occur between the organism level and population level during domestication (or under natural selection). The non-random subsampling of genetic diversity that underlies selection results in a reduction in genetic variation across generations. This lack of variability can make populations of plants or animals less able to adapt to novel challenges such as emerging pests and pathogens or climate change and may affect long-term viability. It is also recognized that artificial selection can cause deleterious mutations to accumulate in domesticated populations for various reasons, including inbreeding and the hitchhiking of deleterious genes along with those under intense artificial selection (e.g., Lu et al. 2006; Cruz et al. 2008). In short, artificial selection for specific features brings with it consequences both for other components of organisms and for the populations of which organisms are a part.

\section{Selection Is Not the only Mechanism of Evolution}

The generation of new heritable variation is not an outcome of selection, rather this occurs by mutation and recombination. Selection is a process by which the frequencies of existing variants changes from one generation to the next, and it is not the only one. The movement of genes from one population to another (gene flow) provides an additional mechanism, and the chance sorting of variants (genetic drift) is yet another. Chance processes are particularly relevant in smaller populations because of the increased probability of drawing an unrepresentative sample of existing diversity. Because it is independent of fitness, genetic drift can cause fit, unfit, or neutral alleles to become fixed. This may be particularly relevant in domestication because of the major bottleneck that this entails.

In some cases, features commonly associated with domestication have not been selected directly but rather represent side effects of the relaxation of selection (e.g., Dobney and Larson 2006). For example, the domestication of animals relaxes the selective pressure on males to compete for mates. This means that genes involved in producing traits relevant to this endeavor (e.g., large horns in male goats) are no longer under selection and become effectively neutral or even detrimental as they involve diversions of resources away from traits such as rapid growth that are under selection. The horns of domesticated livestock can therefore be lost not because humans select directly for their reduction but because a lack of sexual selection allows alleles specifying smaller horns to increase in frequency indirectly or by chance (Mignon-Grasteau et al. 2005; Zeder et al. 2006a). This example is very instructive, as it cautions against interpreting every feature of an organism (domestic or wild) as an adaptation brought about directly through selection.

Lesson 10: Conscious Thought and Long-term Goals Are Not Required for Selection to Operate

Among the most difficult concepts for students to grasp are that natural selection does not actively "select" in any 
conscious sense, that evolution has no long-term goals, and that individual organisms under selection do not attempt to improve in the face of environmental challenges. On the face of it, artificial selection-which does involve the input of conscious selecting agents-may seem to be a very poor model for use in correcting these misconceptions. This superficial interpretation is misleading, however. In fact, an understanding of domestication and artificial selection provides significant clarification on these points.

\section{Crops and Domestic Animals Do Not Consciously Adapt}

The process of artificial selection, whether methodical or unconscious, involves the non-random propagation of randomly varying individuals within an available population. The individual plants and animals under artificial selection do not make any conscious effort to meet the expectations of farmers. They have no understanding of genetics or selection and hold no long-term goal to become domesticated - they simply happen to possess traits of interest or they do not. The selective pressures in the wild are different, but there is no more conscious effort by animals and plants to adapt under natural selection than with artificial selection. Evolution in either case is a process in which gene variants change in proportion from one generation to the next. Conscious effort to pass on one's genes is not necessary to drive this mechanism.

\section{Early Domestication Probably Occurred Through Unconscious Selection}

Whereas methodical selection involves intentional breeding to achieve a predefined ideal form, unconscious selection is not based on striving toward any long-term goal. It is therefore important that, in most cases, early domestication is thought to have occurred through unconscious selection rather than methodical selection (e.g., Darlington 1969; Heiser 1988; Zohary et al. 1998; Doebley et al. 2006; Zeder et al. 2006b; Ross-Ibarra et al. 2007) ${ }^{8}$. As Diamond (2002) explained,

Food production could not possibly have arisen through a conscious decision, because the world's first farmers had around them no model of farming to observe, hence they could not have known that there was a goal of domestication to strive for, and could not have guessed the consequences that domestication would bring for them.

Instead, domestication in seed crops probably began with a very simple input (see Doebley et al. 2006). For

\footnotetext{
${ }^{8}$ In root crops that must be propagated manually, selection may have been methodical from the beginning (Smith 2006).
}

example, the first step may simply have involved burning inedible vegetation to encourage the growth of edible grasses. Being weedy, grasses would have been among the first to occupy these disturbed environments. (Alternatively, the early relationship between edible grasses and humans may have been one in which weeds that easily invaded disturbed areas appeared regularly near seasonal campgrounds used by migrating hunter-gatherers.) From this point, it would have been a small step to not only clearing existing vegetation but also to actively sowing seeds from plants gathered elsewhere and thence to sowing seeds from plants in the same area from season to season. Later, traits that made it easier for seeds to be collected, such as loss of shattering, would have been selectedagain, largely unconsciously because those that shatter simply would have been more difficult to collect. Methodical selection for flavor, color, or other specific features would have occurred only later.

A similar situation probably applies to domesticated animals. In both dogs and livestock, it is thought that the early stages of domestication involved unconscious selection for behavioral traits (e.g., for tameness and reduced aggression; e.g., Jensen 2006; Zeder et al. 2006a, b). In turn, this had significant consequences for physical and developmental features that may have been selected only indirectly. The plausibility of this hypothesis is strengthened by the example of "domesticated" silver foxes, which have been the subject of a decades-long breeding experiment. Specifically, individual foxes have been selected purely on the basis of tameness, but major changes in behavior, development, and appearance have arisen as a result (see Trut 1999). In this case, selection has been intentional, but this mimics a probable unconscious process that occurred early in dog domestication when wolves and humans began coming into close contact.

In some cases, human farming practices may not only be unconscious but may engender unintended and undesirable consequences. For example, by clearing vegetation and tilling fields, humans have established new environments that favor increasingly weedy traits among plants other than the desired crops (Harlan et al. 1973). By definition, unconscious selection involves no goal-directed choices. Rather, it is a process that occurs naturally within the unnatural environment created by human agriculturists. In this regard, many authors have pointed out that there is no fundamental difference between unconscious selection and natural selection (e.g., Darlington 1969; Heiser 1988; Ross-Ibarra et al. 2007).

\section{Domestication Has Caused Humans to Evolve as well}

It is important to note that, as significant as the effects of artificial selection have been on domesticated plants and 
animals, this has not been a one-way interaction. Domestication is, in fact, a coevolutionary process in which both domesticates and human populations experience selection (e.g., Zeder et al. 2006b). In fact, the rise of agriculture is thought to have been a cause of extensive evolution in humans (e.g., Diamond 2002; Hawks et al. 2007). A shift to agriculture from hunting and gathering created a new environment for humans just as it did for plants and livestock. This included a change from high-protein to high-carbohydrate diets and increased disease due to higher population densities and the zoonotic transfer of pathogens from livestock to people (Diamond 1997, 2002). Recent analyses of human genomic data suggest that many genes have been under positive selection in recent history (e.g., Nielsen et al. 2005; Voight et al. 2006; Williamson et al. 2007; Sabeti et al. 2007), including some involved in taste and smell, lactose and sucrose digestion, and disease resistance. The increase in human population size is likely to have been particularly relevant in this regard, given that the total occurrence of new mutations is higher when there are more individuals and because selection is more effective in larger populations (Hawks et al. 2007). Artificial selection has reflected back on the species that imposed it and has been a significant factor in recent evolutionary change among humans.

\section{Concluding Remarks: Darwin's Analogy in the Twenty-first Century}

Artificial selection and domestication featured very prominently in Darwin's published works, being his preferred means of introducing the concept of natural selection and of exploring the mechanisms of variation and inheritance. Although some of Darwin's prominent contemporaries disagreed with it, modern data have vindicated his analogy between domestication by artificial selection and adaptation by natural selection. In fact, studies of domesticated animals and plants continue to serve as an excellent model for investigating the genetic underpinnings of adaptation. Methods used in domestication research are often the same as those applied in evolutionary biology at large, and advances in the two fields continue to be mutually enlightening.

As discussed in this paper, the rapidly expanding knowledge of the history of domestication and the operation of artificial selection provide many important lessons about evolution in general. Whether or not artificial selection was integral in Darwin's discovery of the theory of natural selection, it remains a viable way of explaining and clarifying the mechanism of selection to students. As Darwin himself noted (Notebook E of 1838-1839, p. 71), "It is a beautiful part of my theory, that domesticated races of organics are made by precisely [the] same means as species."
It is a testament to Darwin's insight that artificial selection continues to provide a productive means of both researching and teaching the basic principles of evolution by natural selection.

\section{References}

Allaby RG, Fuller DQ, Brown TA. The genetic expectations of a protracted model for the origins of domesticated crops. Proc Natl Acad Sci U S A 2008;105:13982-6. doi:10.1073/pnas. 0803780105.

Ashikari M, Sakakibara H, Lin S, Yamamoto T, Takashi T, Nishimura $\mathrm{A}$, et al. Cytokinin oxidase regulates rice grain production. Science 2005;309:741-5. doi:10.1126/science.1113373.

Balter M. Seeking agriculture's ancient roots. Science 2007;316:1830-5. doi:10.1126/science.316.5833.1830.

Bartley MM. Darwin and domestication: studies on inheritance. J Hist Biol 1992;25:307-33. doi:10.1007/BF00162844.

Bellwood P. First farmers. Malden: Blackwell; 2005.

Bennetzen J, Buckler E, Chandler V, Doebley J, Dorweiler J, Gaut B, et al. Genetic evidence and the origin of maize. Lat Am Antiquity 2001;12:84-6. doi:10.2307/971759.

Benz BF. Archaeological evidence of teosinte domestication from Guilá Naquitz, Oaxaca. Proc Natl Acad Sci U S A 2001;98:2104-6. doi:10.1073/pnas.98.4.2104.

Bradbury LMT, Fitzgerald TL, Henry RJ, Jin Q, Waters DLE. The gene for fragrance in rice. Plant Biotechnol J 2005;3:363-70. doi:10.1111/j.1467-7652.2005.00131.x.

Bromham L, Penny D. The modern molecular clock. Nat Rev Genet 2003;4:216-24. doi:10.1038/nrg1020.

Brown TA. How ancient DNA may help in understanding the origin and spread of agriculture. Proc R Soc Lond B Biol Sci 1999;354:89-98. doi:10.1098/rstb.1999.0362.

Bruford MW, Bradley DG, Luikart G. DNA markers reveal the complexity of livestock domestication. Nat Rev Genet 2003;4:900-10. doi:10.1038/nrg1203.

Buckler ES, Stevens NM. Maize origins, domestication, and selection. In: Motley TJ, Zerega N, Cross H, editors. Darwin's harvest. New York: Columbia University Press; 2006. p. 67-90.

Burger JC, Chapman MA, Burke JM. Molecular insights into the evolution of crop plants. Am J Bot 2008;95:113-22. doi:10.3732/ ajb.95.2.113.

Cheng C, Tsuchimoto S, Ohtsubo H, Ohtsubo E. Evolutionary relationships among rice species with AA genome based on SINE insertion analysis. Genes Genet Syst 2002;77:323-34. doi:10.1266/ggs.77.323.

Collard BCY, Jahufer MZZ, Brouwer JB, Pang ECK. An introduction to markers, quantitative trait loci (QTL) mapping and markerassisted selection for crop improvement: the basic concepts. Euphytica 2005;142:169-96. doi:10.1007/s10681-005-1681-5.

Cornell JF. Analogy and technology in Darwin's vision of nature. J Hist Biol 1984;17:303-44. doi:10.1007/BF00126367.

Cruz F, Vilà C, Webster MT. The legacy of domestication: accumulation of deleterious mutations in the dog genome. Mol Biol Evol 2008;25:2331-6. doi:10.1093/molbev/msn177.

Darlington CD. The evolution of man and society. London: Allen and Unwin; 1969.

Darwin C. An account of the fine dust which often falls on vessels in the Atlantic ocean. Q J Geol Soc Lond 1846;2:26-30.

Darwin C. On the origin of species by means of natural selection, or the preservation of favoured races in the struggle for life. London: John Murray; 1859. 
Darwin C. The variation of animals and plants under domestication. London: John Murray; 1868.

Darwin C. The autobiography of Charles Darwin 1809-1882. London: Collins; 1958.

Diamond J. Guns, germs, and steel. New York: Norton; 1997.

Diamond J. Evolution, consequences and future of plant and animal domestication. Nature 2002;418:700-7. doi:10.1038/nature01019.

Dobney K, Larson G. Genetics and animal domestication: new windows on an elusive process. J Zool 2006;269:261-71.

Doebley J. Mapping the genes that made maize. Trends Genet 1992;8:302-7.

Doebley J. The genetics of maize evolution. Annu Rev Genet 2004;38:37-59. doi:10.1146/annurev.genet.38.072902.092425.

Doebley J. Unfallen grains: how ancient farmers turned weeds into crops. Science 2006;312:1318-9. doi:10.1126/science.1128836.

Doebley JF, Gaut BS, Smith BD. The molecular genetics of crop domestication. Cell 2006;127:1309-21. doi:10.1016/j.cell.2006. 12.006 .

Drake AG, Klingenberg CP. The pace of morphological change: historical transformation of skull shape in St Bernard dogs. Proc R Soc Lond B Biol Sci 2008;275:71-6. doi:10.1098/rspb.2007. 1169.

Driscoll CA, Menotti-Raymond M, Roca AL, Hupe K, Johnson WE, Geffen E, et al. The near eastern origin of cat domestication. Science 2007;317:519-23. doi:10.1126/science.1139518.

Emshwiller E. Genetic data and plant domestication. In: Zeder MA, Bradley DG, Emshwiller E, Smith BD, editors. Documenting domestication. Berkeley: University of California Press; 2006. p. 99-122.

Eubanks MW. Interdisciplinary perspective on the origin of maize. Lat Am Antiquity 2001;12:91-8. doi:10.2307/971761.

Evans LT. Darwin's use of the analogy between artificial and natural selection. J Hist Biol 1984;17:113-40. doi:10.1007/BF00397504.

Eyre-Walker A, Gaut RL, Hilton H, Feldman DL, Gaut BS. Investigation of the bottleneck leading to the domestication of maize. Proc Natl Acad Sci U S A 1998;95:4441-6. doi:10.1073/pnas.95.8.4441.

Fan C, Xing Y, Mao H, Lu T, Han B, Xu C, et al. GS3, a major QTL for grain length and weight and minor QTL for grain width and thickness in rice, encodes a putative transmembrane protein. Theor Appl Genet 2006;112:1164-71. doi:10.1007/s00122-006-0218-1.

Fitzgerald MA, Sackville Hamilton NR, Calingacion MN, Verhoeven HA, Butardo VM. Is there a second fragrance gene in rice? Plant Biotechnol J 2008;6:416-23. doi:10.1111/j.1467-7652.2008. 00327.x.

Fuller DQ. Contrasting patterns in crop domestication and domestication rates: recent archaeobotanical insights from the Old World. Ann Bot (Lond) 2007;100:903-24. doi:10.1093/aob/mcm048.

Futuyma DJ. Evolution. Sunderland: Sinauer; 2005.

Gepts P. Crop domestication as a long-term selection experiment. Plant Breed Rev 2004;24(2):1-44.

Gildenhuys P. Darwin, Herschel, and the role of analogy in Darwin's origin. Stud Hist Philos Biol Biomed Sci 2004;35:593-611. doi:10.1016/j.shpsc.2004.09.002.

Grant PR, Grant BR. How and why species multiply. Princeton: Princeton University Press; 2008.

Gregory TR. Synergy between sequence and size in large-scale genomics. Nat Rev Genet 2005;6:699-708. doi:10.1038/nrg1674.

Gregory TR. Evolution as fact, theory, and path. Evo Edu Outreach 2008a;1:46-52. doi:10.1007/s12052-007-0001-z.

Gregory TR. Understanding evolutionary trees. Evo Edu Outreach 2008b;1:121-37. doi:10.1007/s12052-008-0035-x.

Gregory TR. The evolution of complex organs. Evo. Edu Outreach 2008c;1:358-89. doi:10.1007/s12052-008-0076-1.

Harlan JR, de Wet JMJ, Price EG. Comparative evolution of cereals. Evolution Int J Org Evolution 1973;27:311-25. doi:10.2307/ 2406971.
Haudry A, Cenci A, Ravel C, Bataillon T, Brunel D, Poncet C, et al. Grinding up wheat: a massive loss of nucleotide diversity since domestication. Mol Biol Evol 2007;24:1506-17. doi:10.1093/ molbev/msm077.

Hawks J, Wang ET, Cochran GM, Harpending HC, Moyzis RK. Recent acceleration of human adaptive evolution. Proc Natl Acad Sci U S A 2007;104:20753-8. doi:10.1073/pnas.0707650104.

Heiser CB. Aspects of unconscious selection and the evolution of domesticated plants. Euphytica 1988;37:77-81. doi:10.1007/ BF00037227.

Herbert S. Darwin, Malthus, and selection. J Hist Biol 1971;4:209-17. doi:10.1007/BF00356983.

Herke SW, Xing J, Ray DA, Zimmerman JW, Cordaux R, Batzer MA. A SINE-based dichotomous key for primate identification. Gene 2007;390:39-51. doi:10.1016/j.gene.2006.08.015.

Ho SYW, Larson G. Molecular clocks: when times are a-changin'. Trends Genet 2006;22:79-83. doi:10.1016/j.tig.2005.11.006.

Hull DL. Darwin and his critics. Cambridge: Harvard University Press; 1973.

Jaenicke-Després V, Buckler ES, Smith BD, Gilbert MTP, Cooper A, Doebley $\mathrm{J}$, et al. Early allelic selection in maize as revealed by ancient DNA. Science 2003;302:1206-8. doi:10.1126/science. 1089056.

Jahren AH, Kraft RA. Carbon and nitrogen stable isotopes in fast food: signature of corn and confinement. Proc Natl Acad Sci U S A 2008;105:17855-60. doi:10.1073/pnas.0809870105.

Jensen P. Domestication - from behaviour to genes and back again. Appl Anim Behav Sci 2006;97:3-15. doi:10.1016/j.applanim. 2005.11.015.

Jin J, Huang W, Gao JP, Yang J, Shi M, Zhu MZ, et al. Genetic control of rice plant architecture under domestication. Nat Genet 2008;40:1365-9. doi:10.1038/ng.247.

Jones M, Brown TA. Agricultural origins: the evidence of modern and ancient DNA. Holocene 2000;10:769-76. doi:10.1191/ 09596830095024.

Jørgensen C, Enberg K, Dunlop ES, Arlinghaus R, Boukal DS, Brander $\mathrm{K}$, et al. Managing evolving fish stocks. Science 2007;318:1247-8. doi:10.1126/science.1148089.

Kawakami S-i, Ebana K, Nishikawa T, Sato Y-i, Vaughan DA, Kadowaki K-i. Genetic variation in the chloroplast genome suggests multiple domestication of cultivated Asian rice (Oryza sativa L.). Genome 2007;50:180-7. doi:10.1139/G06-139.

Kohn D. Theories to work by: rejected theories, reproduction, and Darwin's path to natural selection. Stud Hist Biol 1980;4:67-170.

Konishi S, Izawa T, Lin SY, Ebana K, Fukuta Y, Sasaki T, et al. An SNP caused loss of seed shattering during rice domestication. Science 2006;312:1392-6.

Kovach MJ, Sweeney MT, McCouch SR. New insights into the history of rice domestication. Trends Genet 2007;23:579-87.

Kumar A, Bennetzen JL. Plant retrotransposons. Annu Rev Genet 1999;33:479-532. doi:10.1146/annurev.genet.33.1.479.

Kumar A, Hirochika H. Applications of retrotransposons as genetic tools in plant biology. Trends Plant Sci 2001;6:127-34. doi:10.1016/S1360-1385(00)01860-4.

Larson G, Albarella U, Dobney K, Rowley-Conwy P, Schibler J, Tresset A, et al. Ancient DNA, pig domestication, and the spread of the Neolithic into Europe. Proc Natl Acad Sci U S A 2007;104:15276-81. doi:10.1073/pnas.0703411104.

Leonard JA, Wayne RK, Wheeler J, Valadez R, Guillén S, Vilà C. Ancient DNA evidence for Old World origin of New World dogs. Science 2002;298:1613-6. doi:10.1126/science.1076980.

Li C, Zhou A, Sang T. Rice domestication by reducing shattering. Science 2006;311:1936-9. doi:10.1126/science.1123604.

Lin Z, Griffith ME, Li X, Zhu Z, Tan L, Fu Y, et al. Origin of seed shattering in rice (Oryza sativa L.). Planta 2007;226:11-20. doi:10.1007/s00425-006-0460-4. 
Liolios K, Mavrommatis K, Tavernarakis N, Kyrpides NC. The Genomes On Line Database (GOLD) in 2007: status of genomic and metagenomic projects and their associated metadata. Nucleic Acids Res 2008;36:D475-9. doi:10.1093/nar/gkm884.

Lu J, Tang T, Tang H, Huang J, Shi S, Wu CI. The accumulation of deleterious mutations in rice genomes: a hypothesis on the cost of domestication. Trends Genet 2006;22:126-31. doi:10.1016/j. tig.2006.01.004.

Mackay I, Powell W. Methods for linkage disequilibrium mapping in crops. Trends Plant Sci 2006;12:57-63. doi:10.1016/j.tplants. 2006.12.001.

Mansour A. Utilization of genomic retrotransposons as cladistic markers. J Cell Mol Biol 2008;7:17-28.

Matsuoka Y, Yamazaki Y, Ogihara Y, Tsunewaki K. Whole chloroplast genome comparison of rice, maize, and wheat: implications for chloroplast gene diversification and phylogeny of cereals. Mol Biol Evol 2002;19:2084-91.

Meudt HM, Clarke AC. Almost forgotten or latest practice? AFLP applications, analyses and advances. Trends Plant Sci 2007;12:106-17. doi:10.1016/j.tplants.2007.02.001.

Mignon-Grasteau S, Boissy A, Bouix J, Faure JM, Fisher AD, Hinch GN, et al. Genetics of adaptation and domestication in livestock. Livest Prod Sci 2005;93:3-14. doi:10.1016/j.livprodsci.2004. 11.001.

Miller W, Drautz DI, Ratan A, Pusey B, Qi J, Lesk AM, et al. Sequencing the nuclear genome of the extinct woolly mammoth. Nature 2008;456:387-90. doi:10.1038/nature07446.

Motley TJ. Crop plants: past, present, and future. In: Motley TJ, Zerega N, Cross H, editors. Darwin's harvest. New York: Columbia University Press; 2006. p. 1-27.

Nielsen R, Bustamante C, Clark AG, Glanowski S, Sackton TB, Hubisz MJ, et al. A scan for positively selected genes in the genomes of humans and chimpanzees. PLoS Biol 2005;3:e170. doi:10.1371/journal.pbio.0030170.

Nikaido M, Rooney AP, Okada N. Phylogenetic relationships among cetartiodactyls based on insertions of short and long interspersed elements: hippopotamuses are the closest extant relatives of whales. Proc Natl Acad Sci U S A 1999;96:10261-6. doi:10. 1073/pnas.96.18.10261.

Nikaido M, Hamilton H, Makino H, Sasaki T, Takahashi K, Goto M, et al. Baleen whale phylogeny and a past extensive radiation event revealed by SINE insertion analysis. Mol Biol Evol 2006;23: 866-73. doi:10.1093/molbev/msj071.

Noonan JP, Coop G, Kudaravalli S, Smith D, Krause J, Alessi J, et al. Sequencing and analysis of Neanderthal genomic DNA. Science 2006;314:1113-8. doi:10.1126/science.1131412.

Olsen KM, Caicedo AL, Polato N, McClung A, McCouch S, Purugganan MD. Selection under domestication: evidence for a sweep in the rice waxy genomic region. Genetics 2006;173:97583. doi:10.1534/genetics.106.056473.

Palaisa KA, Morgante M, Williams M, Rafalski A. Contrasting effects of selection on sequence diversity and linkage disequilibrium at two phytoene synthase loci. Plant Cell 2003;15:1795-806. doi: $10.1105 /$ tpc. 012526 .

Palmer JD. Chloroplast DNA and molecular phylogeny. Bioessays 1985;2:263-7. doi:10.1002/bies.950020607.

Palumbi SR. Humans as the world's greatest evolutionary force. Science 2001a;293:1786-90. doi:10.1126/science.293.5536.1786.

Palumbi SR. The evolution explosion. New York: Norton; 2001b.

Panaud O. The molecular bases of cereal domestication and the history of rice. Comptes Rendus Biologies 2008; in press.

Piperno DR, Flannery KV. The earliest archaeological maize (Zea mays L.) from highland Mexico: new accelerator mass spectrometry dates and their implications. Proc Natl Acad Sci U S A 2001;98:2101-3. doi:10.1073/pnas.98.4.2101.
Piperno DR, Weiss E, Holst I, Nadel D. Processing of wild cereal grains in the Upper Palaeolithic revealed by starch grain analysis. Nature 2004;430:670-3. doi:10.1038/nature02734.

Pozzi C, Rossini L, Vecchietti A, Salamini F. Gene and genome changes during domestication of cereals. In: Gupta PK, Varshney RK, editors. Cereal genomics. Dordrecht: Kluwer Academic; 2004. p. 165-98.

Purugganan MD, Boyles AL, Suddith JI. Variation and selection at the CAULIFLOWER floral homeotic gene accompanying the evolution of domesticated Brassica oleracea. Genetics 2000;115:85562.

Rheinberger HJ, McLaughlin P. Darwin's experimental natural history. J Hist Biol 1984;17:345-68. doi:10.1007/BF00126368.

Richards RA. Darwin and the inefficacy of artificial selection. Stud Hist Philos Sci 1997;28:75-97. doi:10.1016/S0039-3681(96) 00008-8.

Ross-Ibarra J, Morrell PL, Gaut BS. Plant domestication, a unique opportunity to identify the genetic basis of adaptation. Proc Natl Acad Sci U S A 2007;104:8641-8. doi:10.1073/pnas.0700643104.

Ruse M. The value of analogical models in science. Dialogue 1973;12:246-53.

Ruse M. Charles Darwin and artificial selection. J Hist Ideas 1975;36:339-50. doi:10.2307/2708932.

Sabeti PC, Varilly P, Fry B, Lohmueller J, Hostetter E, Cotsapas C, et al. Genome-wide detection and characterization of positive selection in human populations. Nature 2007;449:913-8. doi:10.1038/nature 06250 .

Salamini F, Ozkan H, Brandolini A, Schäfer-Pregl R, Martin W. Genetics and geography of wild cereal domestication in the near east. Nat Rev Genet 2002;3:429-41.

Salem AH, Ray DA, Xing J, Callinan PA, Myers JS, Hedges DJ, et al. Alu elements and hominid phylogenetics. Proc Natl Acad Sci U S A 2003;100:12787-91. doi:10.1073/pnas.2133766100.

Savolainen P, Zhang Yp, Luo J, Lundeberg J, Leitner T. Genetic evidence for an East Asian origin of domestic dogs. Science 2002;298:1610-3. doi:10.1126/science.1073906.

Schulman AH, Flavell AJ, Ellis THN. The application of LTR retrotransposons as molecular markers in plants. In: Miller WJ, Capy P, editors. Mobile genetic elements. Totowa: Humana; 2004a. p. 145-73.

Schulman AH, Gupta PK, Varshney RK. Organization of retrotransposons and microsatellites in cereal genomes. In: Gupta PK, Varshney RK, editors. Cereal genomics. Dordrecht: Kluwer Academic; 2004b.

Schweber SS. The origin of the Origin revisited. J Hist Biol 1977;10:229-316. doi:10.1007/BF00572644.

Secord JA. Nature's fancy: Charles Darwin and the breeding of pigeons. Isis 1981;72:163-86. doi:10.1086/352717.

Shedlock AM, Okada N. SINE insertions: powerful tools for molecular systematics. Bioessays 2000;22:148-60. doi:10.1002/ (SICI)1521-1878(200002)22:2<148::AID-BIES6>3.0.CO;2-Z.

Shedlock AM, Takahashi K, Okada N. SINEs of speciation: tracking lineages with retroposons. Trends Ecol Evol 2004;19:545-53. doi:10.1016/j.tree.2004.08.002.

Smith BD. Documenting domesticated plants in the archaeological record. In: Zeder MA, Bradley DG, Emshwiller E, Smith BD, editors. Documenting domestication. Berkeley: University of California Press; 2006. p. 15-24.

Sterrett SG. Darwin's analogy between artificial and natural selection: how does it go? Stud Hist Philos Biol Biomed Sci 2002;33:15168. doi:10.1016/S1369-8486(01)00039-5.

Sweeney M, McCouch S. The complex history of the domestication of rice. Ann Bot (Lond) 2007;100:951-7. doi:10.1093/aob/mcm128.

Sweeney MT, Thomson MJ, Pfeil BE, McCouch S. Caught redhanded: $R c$ encodes a basic helix-loop-helix protein condition- 
ing red pericarp in rice. Plant Cell 2006;18:283-94. doi:10.1105/ tpc. 105.038430 .

Tanno Ki, Willcox G. How fast was wild wheat domesticated? Science 2006;311:1886. doi:10.1126/science.1124635.

Thompson RG. Documenting the presence of maize in Central and South America through phytolith analysis of food residues. In: Zeder MA, Bradley DG, Emshwiller E, Smith BD, editors. Documenting domestication. Berkeley: University of California Press; 2006. p. 82-95.

Trut LN. Early canid domestication: the farm-fox experiment. Am Sci 1999;87:160-9.

Vaughan DA, Lu BR, Tomooka N. The evolving story of rice evolution. Plant Sci 2008;174:394-408.

Vilà C, Savolainen P, Moldonado JE, Amorim IR, Rice JE, Honeycutt $\mathrm{RL}$, et al. Multiple and ancient origins of the domestic dog. Science 1997;276:1687-9. doi:10.1126/science.276.5319.1687.

Voight BF, Kudravalli S, Wen X, Pritchard JK. A map of recent positive selection in the human genome. PLoS Biol 2006;4:e72. doi:10.1371/journal.pbio.0040072.

Vollbrecht E, Sigmon B. Amazing grass: developmental genetics of maize domestication. Biochem Soc Trans 2005;33:1502-6. doi:10.1042/BST20051502.

Vorzimmer P. Darwin's Questions About The Breeding of Animals (1839). J Hist Biol 1969a;2:269-81. doi:10.1007/BF00137278.

Vorzimmer P. Darwin, Malthus, and the theory of natural selection. J Hist Ideas 1969b;30:527-42. doi:10.2307/2708609.

Wallace AR. On the tendency of varieties to depart indefinitely from the original type. Proc Linn Soc Lond 1858;3:53-62.

Wallace AR. Darwinism. London: Macmillan; 1889.

Wang H, Nussbaum-Wagler T, Li B, Zhao Q, Vigouroux Y, Faller M, et al. The origin of the naked grains of maize. Nature 2005;436:714-9. doi:10.1038/nature03863.

Wang E, Wang J, Zhu X, Hao W, Wang L, Li Q, et al. Control of rice grain-filling and yield by a gene with a potential signature of domestication. Nat Genet 2008;40:1370-4. doi:10.1038/ng.220.

Waters CK. Taking analogical inference seriously: Darwin's argument from artificial selection. PSA: Proceedings of the Biennial Meeting of the Philosophy of Science Association 1986; 1986:502-13.

Whitt SR, Wilson LM, Tenaillon MI, Gaut BS, Buckler ES. Genetic diversity and selection in the maize starch pathway. Proc Natl Acad Sci U S A 2002;99:12959-62. doi:10.1073/pnas. 202476999.
Wilkes G. Corn, strange and marvelous: but is a definitive origin known? In: Smith CW, Betrán J, Runge ECA, editors. Corn: origin, history, technology, and production. Hoboken: Wiley; 2004. p. 3-63.

Williamson SH, Hubisz MJ, Clark AG, Payseur BA, Bustamante CD, Nielsen R. Localizing recent adaptive evolution in the human genome. PLoS Genet 2007;3:e90. doi:10.1371/journal.pgen. 0030090.

Wills DM, Burke JM. Chloroplast DNA variation confirms a single origin of domesticated sunflower (Helianthus annuus L.). J Hered 2006;97:403-8. doi:10.1093/jhered/es1001.

Wright SI, Gaut B. Molecular population genetics and the search for adaptive evolution in plants. Mol Biol Evol 2005;22:506-19. doi:10.1093/molbev/msi035.

Wright SI, Bi IV, Schroeder SG, Yamasaki M, Doebley JF, McMullen $\mathrm{MD}$, et al. The effects of artificial selection on the maize genome. Science 2005;308:1310-4. doi:10.1126/science.1107891.

Xing J, Wang H, Han K, Ray DA, Huang CH, Chemnick LG, et al. A mobile element based phylogeny of Old World monkeys. Mol Phylogenet Evol 2005;37:872-80. doi:10.1016/j.ympev.2005. 04.015 .

$\mathrm{Xu}$ JH, Cheng C, Tsuchimoto S, Ohtsubo H, Ohtsubo E. Phylogenetic analysis of Oryza rufipogon strains and their relations to Oryza sativa strains by insertion polymorphism of rice SINEs. Genes Genet Syst 2007;82:217-29. doi:10.1266/ggs.82.217.

Zeder MA, Emshwiller E, Smith BD, Bradley DG. Documenting domestication: the intersection of genetics and archaeology. Trends Genet 2006a;22:139-55.

Zeder MA, Bradley DG, Emshwiller E, Smith BD. Documenting domestication: bringing together plants, animals, archaeology, and genetics. In: Zeder MA, Bradley DG, Emshwiller E, Smith $\mathrm{BD}$, editors. Documenting domestication. Berkeley: University of California Press; 2006b. p. 1-12.

Zhang P, Friebe B, Gill BS. Variation in the distribution of a genomespecific DNA sequence on chromosomes reveals evolutionary relationships in the Triticum and Aegilops complex. Plant Syst Evol 2002;235:169-79.

Zohary D. Unconscious selection and the evolution of domesticated plants. Econ Bot 2004;58:5-10. doi:10.1663/0013-0001(2004) 058[0005:USATEO]2.0.CO;2.

Zohary D, Tchernov E, Kolska Horwitz L. The role of unconscious selection in the domestication of sheep and goats. J Zool 1998;245:129-35. doi:10.1111/j.1469-7998.1998.tb00082.x. 